\title{
ARTICLE
}

\section{REDUCING CRIME BY SHAPING \\ THE BUILT ENVIRONMENT WITH ZONING: AN EMPIRICAL STUDY OF LOS ANGELES}

\section{JAMES M. ANDERSON, JOHN M. MACDONALD, RICKY BLUTHENTHAL \& J. SCOTT ASHWOOD ${ }^{\dagger}$}

The idea of using law to change the built environment in ways that reduce opportunities to commit crimes has a long history. Unfortunately, this idea has received relatively little attention in the legal academy and only limited rigorous empirical scrutiny. In this Article, we review the considerable literature on the relationship between zoning, the built environment, and crime. We then report the results of two empirical studies on these relationships. First, we conducted a study of the effect of zoning on crime using 205 blocks selected in eight different relatively high crime neighborhoods in Los Angeles that have similar demographic characteristics but different forms of zoned land use. We find that mixed commercial-and residential-zoned areas are associated with lower crime than are commercial-only zoned areas. Second, we matched neighborhoods undergoing zoning changes between

$\dagger$ James M. Anderson, J.D. (janderso@rand.org) is a Behavioral and Social Scientist at RAND. John MacDonald is an Associate Professor and the Director of the Jerry Lee Center of Criminology at the University of Pennsylvania. Ricky Bluthenthal is Professor of Medicine in the Department of Preventive Medicine, Keck School of Medicine, at the University of Southern California. J. Scott Ashwood is a Research Programmer at RAND. We would like to thank Heather Guentzel for able data collection, as well as Alex Garvin, Joseph Doherty, Con Howe, Beatrice Pacheco, the City of Los Angeles Planning Department, Hope Plasha, and numerous commentators at the Robert Wood Johnson Public Health Law Research Conferences. We would also like to thank Robert Ellickson of Yale Law School, Paul Heaton of RAND, and Thomas Stucky of Indiana University for their formal peer reviews. The project was inspired by thoughtful papers on the topic by Nicole Garnett and Neal Katyal. This research was funded by the Public Health Law Research program of the Robert Wood Johnson Foundation. We would like to thank the Robert Wood Johnson Foundation and, in particular, Scott Burris and Heidi Grunwald for their support of this research. Finally, we would like to thank Craig Fansler, Ben Grunwald, and the team at the University of Pennsylvania Law Review for their careful edits. 
2006 and 2010 with neighborhoods that underwent no zoning changes during this period but had similar preexisting crime trajectories between 1994 and 2005. The primary zoning change in these neighborhoods was to convert parcels to residential uses. We find that neighborhoods in which there was a zoning change experienced a significant decline in crime. Our results suggest that mixing residential-only zoning into commercial blocks may be a promising means of reducing crime.

INTRODUCTION

I. BACKGROUND ON LAND USE LAW, THE BUILT

ENVIRONMENT, AND CRIME .........................................705

A. The Development of Land Use and Planning Law ........................ 706

B. History of Land Use Regulation in Los Angeles ............................. 709

II. EXISTING RESEARCH ON THE RELATIONSHIP BETWEEN

LAND USE, THE BUILT ENVIRONMENT, AND CRIME............... 711

A. Land Use ................................................................. 711

B. Natural Surveillance ........................................................ 712

C. Target-Hardening ...................................................... 715

D. Territoriality and Permeability .................................................716

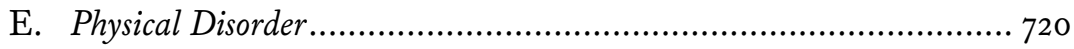

F. Crime Attractors/Reducers ...............................................723

G. Density .....................................................................725

H. Limits to Existing Research .............................................. 726

III. EMPIRICAL ANALYSIS OF THE EFFECT OF LAND USE LAW

ON THE BUILT ENVIRONMENT AND CRIME ..........................727

A. Sample Construction ....................................................... 729

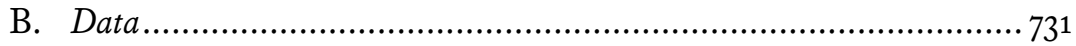

1. Land Use Data.................................................. $73^{1}$

2. Crime Data ....................................................... $73^{2}$

3. Built Environment Data ..........................................733

C. Results .................................................................... 734

1. The Association Between Zoning

Classifications and Crime............................................ 734

2. The Association Between Zoning

Homogeneity and Crime ..............................................738

3. The Association Between Zoning and the Built Environment ...................................... 742

4. The Built Environment as a Mediator for the Association Between Land Use and Crime ...................... 744

IV. EMPIRICAL ANALYSIS OF THE EFFECT OF ZONING CHANGES ON CRIME. 
A. Data

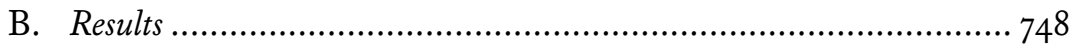

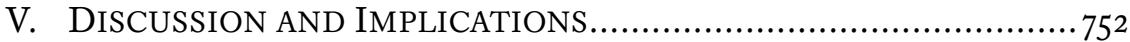

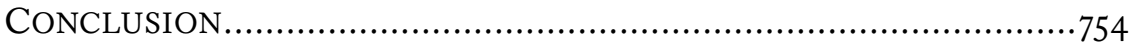

It is likewise commanded that the highways from market towns to other market towns be widened where there are woods or hedges or ditches, so that there be no ditch, underwood or bushes where one could hide with evil intent within two hundred feet of the road on one side or the other side .... And if perchance there is a park near the highway, it will behove the lord of the park to reduce his park until there is a verge two hundred foot wide at the side of the highway, as aforesaid, or to make a wall, ditch or hedge that malefactors cannot get over or get back over to do evil.

-King Edward I, Statute of Winchester, $1285^{1}$

\section{INTRODUCTION}

Policymakers have long sought to use law to shape the physical environment to reduce crime. Such efforts date at least as far back as the Statute of Winchester in 1285, in which King Edward I required the widening of highways and removal of bushes that provided cover to robbers. ${ }^{2}$ More recently, legal academics have proposed that land use law should be used by policymakers to reduce crime. ${ }^{3}$

The attraction of such a strategy is considerable. Traditionally, criminal law has sought to reduce crime by deterring, rehabilitating, or incapacitating

1 Statute of Winchester, 1285,13 Edw., c. 5 (Eng.), reprinted in 3 ENGLiSH HistoriCAL DOCUMENTS 1189-1327, at 461 (Harry Rothwell ed., 1975).

2 For a discussion of these provisions of the statute and their antecedents, see Henry Summerson, The Enforcement of the Statute of Winchester, 1285-1327, 13 J. LEGAL HIST. 232, 233 (1992).

3 See Nicole Stelle Garnett, Ordering the City: Land Use, Policing, and THE RESTORATION OF URBAN AMERICA 101-11 (2010) (describing the various "land-management strategies" that city officials have used to combat crime as an alternative to policing, such as "homeless campuses, 'neighborhood exclusion zones,' and regulatory 'sweeps"'); Nicole Stelle Garnett, Ordering (and Order in) the City, 57 STAN. L. REV. 1, 12 (2004) [hereinafter Garnett, Ordering] (" $[\mathrm{G}]$ overnment choices about the uses of property also dramatically affect [the ordermaintenance of order within] an urban environment without raising the same constitutional concerns [as] police discretion."); Nicole Stelle Garnett, The People Paradox, 2012 U. ILL. L. REV. 43, 47 [hereinafter Garnett, The People Paradox] (arguing that mixed-land use urban development may be justified because people feel safer in busier neighborhoods, despite evidence that commercial activity is associated with crime). See generally Neal Kumar Katyal, Architecture as Crime Control, 111 YALE L.J. 1039 (2002); Edward H. Ziegler, American Cities, Urban Planning, and Place-Based Crime Prevention, 39 URB. LAW. 859, 869-73 (2007) (reviewing the typical processes by which cities implement place-based crime control efforts). 
potential criminals, but it has taken little account of spatial or situational factors. ${ }^{4}$ Unfortunately, this approach has sometimes proved disappointing in practice. For example, sentencing reforms that emphasized deterrence through the enactment of mandatory minimum sentences ${ }^{5}$ have shown little relationship with actual crime trends. ${ }^{6}$ Meanwhile, rehabilitation efforts have been abandoned for many adult offenders in the United States. ${ }^{7}$ Incapacitation is expensive, has limited effects on crime, and imposes other substantial social costs. ${ }^{8}$ Most crimes are not even reported, much less solved, again limiting the efficacy of the conventional criminal law in reducing crime. ${ }^{9}$

4 See Adam Benforado, The Geography of Criminal Law, 31 CARDOZO L. REV. 823, 837 (2010) (noting that western criminal law "tend[s] to focus on dispositional factors at the expense of more critical situational factors" when seeking to understand criminal events, rather than important physical-spatial elements).

5 James Q. Wilson, Thinking AbOUt CRime 133-37 (rev. ed. 1983).

6 Michael Tonry, The Mostly Unintended Effects of Mandatory Penalties: Two Centuries of Consistent Findings, in 38 CRIME AND JUSTICE: A REVIEW OF RESEARCH 65, 68-69 (Michael Tonry ed., 2009). But see Eric Helland \& Alexander Tabarrok, Does Three Strikes Deter?: A Nonparametric Estimation, 42 J. HUM. RESOURCES 309, 326-28 (2007) (finding that California's threestrikes law has a significant deterrent effect among criminals with two strikes).

7 See Marie Gottschalk, The Prison and the Gallows: The Politics of MASS INCARCERATION IN AMERICA 38-40 (2006) (tracing how dissatisfaction with sentencing practices gradually led to the abandonment of rehabilitation as a goal).

8 See William SPELMAN, CRIMINAL INCAPACITATION 220-21 (1994) (finding that incapacitation has a -0.20 elasticity with regards to crime, suggesting that a $10 \%$ increase in incarceration produces a $2 \%$ decrease in crime); FRANKLIN E. ZIMRING \& GORDON HAWKINS, INCAPACITATION: PENAL CONFINEMENT AND THE RESTRAINT OF CRIME 74-75 (1995) (finding little evidence of crime reductions from incapacitation given the overall diversity of offending, the relatively low probability of apprehension and conviction upon arrest, and the replacement population of offending); Thomas B. Marvell \& Carlisle E. Moody, Jr., Prison Population Growth and Crime Reduction, 10 J. QuAntitative CRIMINOlOGY 109, 129-33 (1994) (using state-level differences in incarceration rates over time to calculate a - 0.16 elasticity of incarceration on crime); see also Steven D. Levitt, The Effect of Prison Population Size on Crime Rates: Evidence from Prison Overcrowding Litigation, 111 Q.J. ECON. 319, 323-24 (1996) (demonstrating a larger incapacitation effect of -0.30 elasticity for property crimes and -0.40 for violent crimes after controlling for simultaneity bias by using shifts in prison populations following successful prison overcrowding litigation). However, these larger effects are only true for the relative shift in people actually sentenced to prison, not on all motivated offenders, which is likely much lower. See Rucker Johnson \& Steven Raphael, How Much Crime Reduction Does the Marginal Prisoner Buy?, 55 J.L. \& ECON. 273, 302 (2012) (finding a much smaller crime-reduction effect for recent increases in incarceration rates).

9 See Jennifer L. Truman \& Michael R. Rand, U.S. DeP'T of Justice, NCJ 231327, CRIMINAL VICTIMIZATION, 2009, at 1 (2010) (noting that only about half of all violent crimes and two-fifths of all property crimes were reported to the police); FBI, CRIME IN THE UNITED STATES 2009, at tbl.25 (2010), available at http://www2.fbi.gov/ucr/cius2009/data/table $25 . \mathrm{html}$ (showing less than a fifty-percent clearance rate by arrest for violent crimes by federal agencies). 
Using land use law to reduce crime sidesteps both of these problems and also the overworked criminal justice system. ${ }^{10}$ By shaping the built environment, policymakers can theoretically eliminate crime by design. ${ }^{11}$

This idea has received considerably more attention in the urban planning literature than in legal scholarship. Jane Jacobs' The Death and Life of Great American Cities noted the importance of the built environment on crime rates and argued for development policies that encouraged diverse land uses to create a vital urban environment and encourage "eyes on the street"12 to deter crime. ${ }^{13}$ In 1968, Shlomo Angel proposed reducing crime though design. ${ }^{14}$ In 1971, C. Ray Jeffery published Crime Prevention through Environmental Design ${ }^{15}$ which was followed by Oscar Newman's publication

10 Many of the hypothesized mechanisms used by land use law are related to deterrence and incapacitation but on a more local level. Land use law that attempts to reduce crime by increasing visibility is a form of localized deterrence. Similarly, "target hardening" anti-crime measures are a form of local incapacitation that keep criminals out of certain areas, rather than confining them to prisons. This is also related to what has been called "third-party policing." See Michael E. Buerger \& Lorraine Green Mazerolle, Third-Party Policing: A Theoretical Analysis of an Emerging Trend, 15 JUST. Q. 301, 301-03 (1998) (defining third-party policing as providing incentives to, or coercing, nonoffenders, especially guardians of property where lawlessness may occur-like bar owners and landlords - to take actions which are outside the scope of their routine activities and which are designed indirectly to minimize disorder and thereby reduce crime); Cecelia Klingele et al., Reimagining Criminal Justice, 2010 WIS. L. REV. 953, 969-70 (noting problems with the existing enforcement paradigm of criminal justice and calling for situational crime prevention as a key goal of any criminal justice system).

11 Early-twentieth century criminologists also focused on the role of the built environment on crime. See, e.g., ROBERT E. PARK ET AL., THE CITY 25 (1925) (claiming that the design of cities affects social interaction, which in turn affects crime); Louis Wirth, Urbanism as a Way of Life, 44 AM. J. SOC. 1, 16 (1938) ("The necessary frequent movement of great numbers of individuals in a congested habitat gives occasion to friction and irritation."). For earlier studies that focused on the role of geography as a causal factor in crime, see M.A. QUETELET, A TREATISE ON MAN AND THE DEVELOPMENT OF HIS FACUlTiES 84-90 (Edinburgh, William \& Robert Chambers 1842). See also John Glyde, Jr., Localities of Crime in Suffolk, 19 J. STAT. SOC'Y LONDON 102, 103 (1856) (comparing relatively higher crime levels in towns "where labourers aggregate together" to lower rates in rural districts).

12 The phrase as originally written was "eyes upon the street." JANE JACOBS, THE DEATH AND LIFE OF GREAT AMERICAN CITIES 35 (1961). However, most subsequent commentary uses "eyes on the street." See, e.g., Katyal, supra note 3, at 1050. We use this more popular version throughout this Article.

13 JACOBS, supra note 12, at 35-36. Even prior to Jacobs's work, University of Chicago sociologists focused on the importance of spatial relationships in understanding crime. See, e.g.,

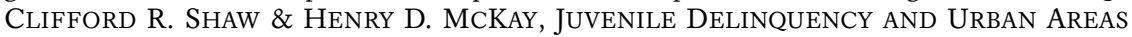
315 (1942) (noting that rates of delinquency remained relatively constant in certain areas of Chicago despite demographic changes).

14 See Shlomo Angel, Discouraging Crime Through City Planning 7-15 (Ctr. for Planning \& Dev. Research, Univ. of Cal. Berkeley, Working Paper No. 75, 1968) (recognizing that "manipulation of the physical environment" can reduce the "number and intensity of criminal opportunities").

15 C. RAY JefFERY, CRIME PREVEntion through EnVIRONMENTAL DESIGN (1971). 
of the influential Defensible Space: Crime Prevention Through Urban Design in $1972 .{ }^{16}$ The field of public health has also begun to pay increased attention to the way in which the design of communities affects a wide array of health outcomes, including violent crime. ${ }^{17}$

Despite the theoretical attractiveness of this idea, and a profusion of many ostensibly plausible theories about the interrelationship between land use law, the built environment, and crime, there has been relatively limited high-quality empirical research on the topic generally and almost no empirical research on this topic in the legal academy specifically. Only recently have legal scholars considered the relationship between the built environment and crime, as well as the opportunities to shape the built environment through land use regulation. ${ }^{18}$ Even so, discussions of this topic have remained speculative at best and have not faced rigorous empirical tests, due in part to the unavailability of micro-level data on both land use regulation and crime patterns.

In this Article, we examine the relationship between zoning, the built environment, and crime by testing a variety of hypotheses suggested by the previous literatures on this subject. We take advantage of the detailed block-level crime data of Los Angeles and the systematic social observations

16 Oscar newman, Defensible Space: Crime Prevention Through Urban DESIGN (1972). Other authors of this era also suggested a connection between the physical environment and crime. See, e.g., RICHARD A. GARDINER, DESIGN FOR SAFE NEIGHBORHOODS 4 (1978) (arguing that redesign of the physical environment is an important and overlooked crime-prevention tool); Stephanie W. Greenberg et al., Safety in Urban Neighborhoods: A Comparison of Physical Characteristics and Informal Territorial Control in High and Low Crime Neighborhoods, 5 POPULATION \& ENV'T 141, 161 (1982) (concluding that differences in the built environment distinguish between high- and low-crime neighborhoods even more than differences in informal territorial control).

17 See, e.g., Richard J. Jackson \& Stacy Sinclair, Designing Healthy CommuNITIES 35 (2012) (arguing that a root cause of many public health problems is the design of the physical environment); William C. Sullivan \& Chun-Yen Chang, Mental Health and the Built Environment (discussing the health consequences of living in a violent neighborhood and the prospect of deterring crime through design), in MAKING HEALTHY PlacES: DESIGNING AND BUILDING FOR HEALTH, WELl-BEING, AND SUSTAINABILITY 106, 113 (Andrew L. Dannenberg et al. eds., 2011); Deborah A. Cohen et al., The Built Environment and Collective Efficacy, 14 HEALTH \& PLACE 198, 205 (2008) (finding that parks were positively associated with the collective efficacy of neighborhoods); Julie Samia Mair \& Michael Mair, Violence Prevention and Control Through Environmental Modifications, 24 ANN. REV. PUB. HEALTH 209, 211-21 (2003) (reviewing research on the connection between the built environment and crime).

18 See Garnett, Ordering, supra note 3, at 3 (discussing the role of property regulation in order-maintenance policing); Katyal, supra note 3, at 1090-1127 (noting and discussing opportunities for the government to reduce crime through architecture); see also Robert C. Ellickson, Controlling Chronic Misconduct in City Spaces: Of Panhandlers, Skid Rows, and Public-Space Zoning, 105 YALE L.J. $1165,1171-72$ (1996) (recognizing the relationship between open-access public spaces, public order, and crime, and positing that zoning should be used for public lands to maintain street order). 
conducted on 205 blocks in eight relatively high-crime areas of Los Angeles. We supplement this data with a Los Angeles-wide analysis of the relationship between changes in land use zones and crime in neighborhoods.

We focus on relatively high-crime neighborhoods because of the pressing policy need to reduce crime in such distressed areas. Using Los Angeles as our study site also complements the limited existing literature on the effect of land use on crime- a literature that mostly focuses on older cities with a different pattern of development. ${ }^{19}$ An important improvement over previous research is that we were able to use a stronger research design ${ }^{20}$ and discuss ways the regulatory framework around land use can be used to reduce crime.

Our central finding is that blocks that include both residential and commercial zoning exhibit less crime than blocks that are zoned exclusively for commercial use. This result suggests that including some parcels with residential-only zoning on blocks that are otherwise zoned commercially might reduce crime. We also find that crime rates are lowest in residentialonly blocks, even in relatively high-crime neighborhoods. Finally, we find that when neighborhoods undergo some change in zoning-mostly toward residential forms - crime drops more than it does in neighborhoods that had comparable crime trends prior to the zoning change that occurred.

We organize this Article by first providing background about land use law and Los Angeles before turning to a review of the sizable literatures in criminology and urban planning that address the relationship between the built environment and crime. We then recount our results and conclude with implications for policymakers.

\section{BACKGROUND ON LAND USE LAW, THE BUILT ENVIRONMENT, AND CRIME}

Land Use law, zoning, and the built environment are related yet distinct concepts. Zoning is one example of land use law, which also includes building and housing codes. Zoning typically prohibits or permits certain uses of property. A property may be zoned for some particular use or uses and yet remain vacant. Land use is how a particular parcel is in fact used. The built environment refers to what is actually present on the land and can include not just the building but also the sidewalk and the distance from the

19 Los Angeles differs from eastern cities in its density pattern. Instead of having a very dense urban core surrounded by less-dense suburbs, the density of Los Angeles is spread more evenly. ROBERT BRUEGMANN, SPRAWL: A COMPACT HistORY 65 (2005).

20 Past research in this area has typically used relatively small samples and very simple crosssectional designs. We use a more sophisticated matching strategy that overcomes some of the limitations in the earlier research. For further discussion of these issues, see infra, Parts III \& IV. 
building to the street-in other words, the whole constructed physical environment. The built environment is often closely connected to social aspects of the environment, including signs of physical decay and disorder.

\section{A. The Development of Land Use and Planning Law}

While the common law has long addressed issues of land use, ${ }^{21}$ an important milestone in the development of modern land use and planning law occurred in 1909, when the United States Supreme Court upheld the authority of Boston to create differential height districts in Welch $v$. Swasey. ${ }^{22}$ Later that same year, the City of Los Angeles divided itself into industrial and residential districts; it also banned industrial activities within residential districts. ${ }^{23}$ Finally, the First National City Planning Conference was held in Washington, D.C., that same year. Adherents of planning, including Frederick Law Olmsted, Jr., advocated the use of "land use districting," as zoning was then known. ${ }^{24}$

Building on these antecedents, New York City is generally credited with enacting the first modern zoning ordinance in $1916 .{ }^{25}$ By 1921 , nearly half of the states had passed zoning-enabling acts, which allowed municipalities within those states to pass zoning ordinances. ${ }^{26}$ By 1926,564 municipalities

21 Nuisance law, for example, was often concerned with inconsistent uses of land. See 2 WILLIAM BLACKSTONE, COMMENTARIES *402-03 ("If my neighbour makes a tan-yard, so as to annoy and render less salubrious the air of my house or gardens, the law will furnish me with a remedy."). For an interesting discussion of nuisance law as a combination of an exclusion regime and tort-like governance rules, see generally Henry E. Smith, Exclusion and Property Rules in the Law of Nuisance, 90 VA. L. REV. 965, 1046 (2004). Restrictive covenants and easements were two other means by which the common law addressed land use issues. See Robert C. Ellickson, Alternatives to Zoning: Covenants, Nuisance Rules, and Fines as Land Use Controls, 40 U. CHI. L. REV. 681, 779-81 (1973) (criticizing zoning as generally creating more problems than it solves and proposing the use of restrictive covenants, nuisance rules (promulgated by "Nuisance Boards"), and fines as a superior alternative approach to "achieving the fundamental goals of a land use control systemefficiency and equity").

22214 U.S. 91, 107-08 (1909). Even prior to 1909, cities used fire limits, building codes, and single-purpose districting in an effort to address growth-related problems. See Kathy A. Kolnick, Order Before Zoning: Land Use Regulation in Los Angeles 1880-1915, at 5 (May 2008) (unpublished Ph.D. dissertation, University of Southern California), available at http://books.google.com/books/ about/Order_Before_Zoning_Land_Use_Regulation.html?id=HHMj3AOyoqMC (noting that local regulations governing land use proliferated across the country prior to 1916).

23 The United States Supreme Court upheld this action when it was challenged as a violation of the Constitution in Hadacheck v. Sebastian, 239 U.S. 394, 412-14 (1915).

24 Kolnick, supra note 22, at 18.

25 Julian CONRAD JUERgEnSmeyer \& THOMAS E. Roberts, LAND Use PlanNing AND DEVELOPMENT REGULATION LAW 23 (2d ed. 2007).

$26 \mathrm{Id}$. 
had passed such ordinances. ${ }^{27}$ Property owners, however, challenged zoning as a restriction on their rights to control their property. The United States Supreme Court largely resolved lingering concerns over the constitutionality of zoning when it upheld zoning as a valid use of the police power in Village of Euclid v. Ambler Realty Co. ${ }^{28}$

Exclusionary zoning was popular because it could protect existing residential land uses. ${ }^{29}$ Particularly in an era in which unsightly, pollution- and noise-generating industry made up a much higher proportion of urban employment, the merits of separating industrial from residential sections of the city seemed self-evident. As James Metzenbaum, the attorney for the Village of Euclid, successfully argued, zoning is "good housekeeping" that results in improvements in community health, safety, and general welfare. ${ }^{30}$

Zoning reformers argued that zoning promoted the single-family home and the domestic life with which it was associated. ${ }^{31}$ Proponents believed that commercial activity facilitated crime and should take place outside residential areas. The Louisiana Supreme Court noted that "[a] place of business in a residence neighborhood furnishes an excuse for any criminal to go into the neighborhood, where, otherwise, a stranger would be under the ban of suspicion." 32 Similarly, the Court of Common Pleas of Cuyahoga

27 Id. at 24 .

28272 U.S. 365 (1926).

29 See GARNETT, supra note 3, at 34 (noting that zoning "guaranteed stable property values and tax revenues" and "empower[ed] local governments to exclude unwanted land uses"); William A. Fischel, An Economic History of Zoning and a Cure for its Exclusionary Effects, 41 URB. STUD. 317, 321 (2004) (arguing that the advent of motorized trucks around 1905 promoted the decentralization of industry and its movement away from city centers, which increased the use of zoning to protect suburban residential neighborhoods); Andrew J. Cappel, Note, A Walk Along Willow: Patterns of Land Use Coordination in Pre-Zoning New Haven (1870-1926), 101 YALE L.J. 617, 634 (1991) (discussing the adoption of zoning in New Haven, Connecticut, as a response to homeowners' fears about the inadequacy of pre-zoning land use agreements "in the face of large-scale demographic and technological change").

301 James MetZenbaum, The LAW OF ZONing 6o-62 (2d ed. 1955). The disadvantages of zoning were recognized by the first judge to consider the constitutionality of zoning, who noted that communities could group "the population and segregate them according to their income or situation in life.” Ambler Realty Co. v. Village of Euclid, 297 F. 307, 316 (N.D. Ohio 1924), rev'd, 272 U.S. 365 . While zoning was popular, it did not typically include comprehensive planning, such as planning for public transit, streets, parks, or the future growth of the city. See JUERGENSMEYER \& ROBERTS, supra note 25 , at 24-26 (discussing how zoning became more popular than, and eventually displaced, comprehensive planning).

31 See Miller v. Bd. of Pub. Works, 234 P. 381, 386-87 (Cal. 1925) ("[R]esidential zoning may, in the last analysis, be rested upon the protection of the civic and social values of the American home . . . . and the fostering of home life doubtless tends to the enhancement, not only of community life, but of the life of the nation as a whole.").

32 State ex rel. Civello v. City of New Orleans, 97 So. 440, 444 (La. 1923); see also GARNETT, supra note 3, at 39 (citing an argument by a zoning proponent that "by segregating 
County, Ohio, noted that "[ $t$ ]he number of people passing in and out [of mixed-use districts] render immoral practices therein more difficult of detection and suppression." ${ }^{33}$

While it might seem odd today, the mixture of residential and commercial uses was considered almost self-evidently undesirable. ${ }^{34}$ Take, for example, the Ohio Supreme Court's explanation of the justifications for zoning: "The entrance of business blocks into a residence district tends to 'blight' the district and gradually to invite therein the hazards, both physical and moral, which exist in the sections which combine business with home life." 35

In 1961, Jane Jacobs published The Death and Life of Great American Cities, a blistering critique of the conventional planning wisdom of the day, which she argued was as unscientific as bloodletting in the history of medicine. ${ }^{36} \mathrm{Her}$ central argument was that a healthy big-city street has multiple simultaneous uses and that efforts to geographically organize the city into single-purpose uses are profoundly misguided, regardless of whether the organization results from large-scale redevelopment or conventional exclusionary zoning. ${ }^{37}$

More recently, there have been attempts to update zoning to encourage more nuanced development patterns under the general banner of New Urbanism. In 1994, the American Planning Association began to update standard planning- and zoning-enabling acts in their Growing Smart Project and published exemplar growth codes, which included mixed-use developments, town centers, affordable housing, transferable development rights, and pedestrian overlay districts. ${ }^{38}$

In general, there has been a partial shift from use-based codes to formbased codes, as well as an increasing effort to reduce sprawl and encourage more urban "in-fill" development. ${ }^{39}$ The touted benefits of such development

residential and commercial land uses, zoning could minimize . . . the 'negative social-influence effects' of urban life," and noting the subtext of Social Darwinist arguments).

33 State ex rel. Morris v. City of East Cleveland, 22 Ohio N.P. (n.s.) 549, 554-55 (C.P. Cuyahoga County 1920).

34 Part of this change in understanding may be explained by the evolution of the typical commercial establishment. Today, we might think of a Starbucks or a boutique. In that era, the fishmonger, butcher, or similar occupations that involved substantial local negative externalities might have come immediately to mind.

35 Pritz v. Messer, 149 N.E. 30, 35 (Ohio 1925), overruled on other grounds, Village of Hudson v. Albrecht, Inc., 458 N.E.2d 852 (1984).

36 JACOBS, supra note 12, at 12.

37 Id. at $152-77$ (explaining that a mixture of residential and commercial uses in a city improves economic prosperity).

38 JUERGENSMEYER \& ROBERTS, supra note 25, at 62.

39 See, e.g., ANDRES DuAnY ET AL., SMARTCODE \& MANUAL C1, C16 (2006) (arguing for the adoption of the SmartCode, a form-based code that "encourages a certain physical 
include less reliance on the automobile, less time spent commuting, less pollution, less need for unsightly parking lots, more exercise, ${ }^{40}$ a reduced environmental impact ${ }^{41}$ and, notably for our purposes, less crime. ${ }^{42}$

Others have leveled a broader critique at zoning itself and suggested that zoning laws prevent the patterns of mixed use development that are "an essential element in the[] stability and vitality" of poor neighborhoods. ${ }^{43}$ One defender of a no-zoning regime noted that " $[t]$ he ability to establish a business in one's garage or home contributes to easy entry of individuals into the economic system." ${ }^{4}$ Similarly, Garnett has suggested that, in low-income neighborhoods, "the addition of a new bodega, hairbraiding salon, or auto repair business might lead to less disorder, not more, by generating the foot traffic that Jacobs and the new urbanists argue fosters healthy and safe street life." 45

\section{B. History of Land Use Regulation in Los Angeles}

Turning to our study site, Los Angeles has a long history of zoning classifications that regulate land use. The history of land use regulation in Los Angeles began in 1573, when Philip II of Spain issued the Laws of the Indies, which governed the establishment of cities in Spanish America, including Los Angeles. ${ }^{46}$ The code included detailed instructions for the

outcome," in order to "establish a human habitat that promotes the health, safety and welfare of the community, while conserving land and resources"); Chad D. Emerson, Making Main Street Legal Again: The SmartCode Solution to Sprawl, 71 MO. L. REV. 637, 638-45 (2006) (asserting that "use-based zoning ordinances are now one of the leading factors in inducing . . sprawl" and that the SmartCode is replacing these use-based codes).

40 See Brian E. Saelens et al., Environmental Correlates of Walking and Cycling: Findings From the Transportation, Urban Design, and Planning Literatures, 25 ANNALS BEHAV. MED. 80, 83 (2003) (finding that residents in areas with higher density, greater street connectivity, and more mixed land use tend to walk and ride bicycles more often for transportation purposes).

41 See Congress for THE NEW URbanism, CHARTER OF THE NEW URbanism, (2001), available at http://www.cnu.org/sites/files/charter_english.pdf (recognizing that environmental health cannot be "sustained without a coherent and supportive physical environment").

42 Richard H. Schneider \& Ted Kitchen, Crime Prevention AND The Built ENVIRONMENT 45, 52-53 (2007) (noting New Urbanism's claims of crime reduction and the lack of evidence supporting them).

43 StUART M. BUTLER, ENTERPRISE ZONES: GREENLINING THE INNER CITIES 56 (1981).

$44 \mathrm{Id}$.

45 Nicole Garnett, Ordering, supra note 3, at 42; see also id. at 5 (examining arguments that the "prevailing system of land use regulation-zoning-may devastate city neighborhoods by stifling the entrepreneurial energies of inner-city residents and precluding the diversity of uses needed for a healthy street life").

46 John W. Reps, The Future of American Planning-Requiem or Renascence?, in LAND USE COnTrols: Q. REV., no. 2, 1967, at 1, 1-16; see also Axel I. Mundigo \& Dora P. Crouch, The City 
location of "slaughter houses, fisheries, tanneries, and other businesses which produce filth." ${ }^{47}$ Similarly, these laws required the construction of arcades around the central plaza, "for these are of considerable convenience to the merchants who generally gather there." 48 In the 188 os, modern land use regulation began when Los Angeles and San Francisco passed ordinances regulating the location of laundries. ${ }^{49}$ By 1915, Los Angeles was zoned into a large residential district, twenty-seven industrial districts, and about onehundred "residence exception districts," which permitted most uses. ${ }^{50} \mathrm{In}$ California, as elsewhere, the promotion and protection of the single-family zone was critical. As the California Supreme Court explained, in affirming the exclusion of multi-family buildings from a single-family zone:

The establishment of such districts is for the general welfare because it tends to promote and perpetuate the American home. . . The character and quality of manhood and womanhood are in a large measure the result of home environment. . . [A] single family home [is] more desirable for the promotion and perpetuation of family life than an apartment, hotel, or flat. ${ }^{51}$

This protection of the single-family home was consistent with the perceived purpose of exclusionary zoning throughout the nation. ${ }^{52}$

The current Los Angeles zoning ordinance includes a blizzard of classifications: twenty-five separate parcel-level residential zoning codes, seven commercial zones, five manufacturing zones, and two special parking zones. ${ }^{53}$ Each of these has additional height districts that restrict both the absolute height ${ }^{54}$ of the building and the floor area ratio (FAR). ${ }^{55}$ In addition,

Planning Ordinances of the Laws of the Indies Revisited, Part 1: Their Philosophy and Implications, 48 TOWN PLAN. REV. 247, 248 (1977).

47 Mundigo \& Crouch, supra note 46 , at 255.

48 Id.

49 Nat'l Comm'n on Urban Problems, Building the American City, H.R. DOC. NO. 91-34, at 200 (1st Sess. 1968).

$50 \mathrm{Id}$. at 200 n.6.

51 Miller v. Bd. of Pub. Works, 234 P. 381, 386-87 (Cal. 1925).

52 See supra text accompanying notes $29-35$.

53 L.A., CAL., MUNICIPAL CODE ch. I, $\S 12.04$ (2012), available at http://www.amlegal. $\mathrm{com} / \mathrm{nxt} /$ gateway.dll?f=templates $\& \mathrm{Fn}=$ default.htm\&vid=amlegal:lapz_ca. "Zoning" can refer to one of three things: "macro"-level issues (e.g., "That section of the city is zoned for industry"), micro-level issues (e.g., "This parcel is zoned for commercial use"), or issues somewhere inbetween (e.g., "That block is commercially zoned"). Thus, while multiple city blocks can be classified within the same zone, zoning operates at the parcel-level. Somewhat confusingly, "mixed-use zoning" is not, in fact a specific kind of zone in Los Angeles; rather it refers to the practice of having multiple kinds of zones in close proximity. This was considered undesirable in traditional zoning practice which generally sought to segregate residential uses from other uses.

54 Id. $§ 12.21 .1$. 
there are supplemental-use districts that regulate uses such as oil drilling, animal slaughtering, and surface mining. ${ }^{56}$

\section{EXISTING RESEARCH ON THE RELATIONSHIP BETWEEN LAND USE, THE BUILT ENVIRONMENT, AND CRIME}

Despite occasional suggestions that land use regulation could be an important tool in reducing crime, existing research generally has not identified specific modifications to the built environment that can effectively reduce crime and violence. While no shortage of plausible hypotheses exist about the relationship between land use, the built environment, and crime, there is little high quality empirical research investigating many of these relationships.

In this Part, we review more mechanisms by which land use and the built environment might affect crime and assess the empirical evidence supporting them. For analytic purposes, we divide these mechanisms into Land Use, Natural Surveillance, Target Hardening, Territoriality and Permeability, Physical Disorder, Crime Attractors/Reducers, and Density. The mechanisms are often related, so any effort to categorize them is somewhat unsatisfactory. For example, one of the reasons that territoriality is important is because it seems to enhance natural surveillance. Yet, as is sometimes the case in an interdisciplinary literature review, different disciplines (in this case, urban planning and criminology) take different approaches to the same (or very similar) underlying issues. Despite that caveat, it seems useful for analytic purposes to divide the numerous studies into these groups.

\section{A. Land Use}

While there has been little research on the effect of zoning on crime, ${ }^{57}$ there has been considerable research on the related issue of the effect of different kinds of land use on crime. In general, research has concluded that, contrary to Jane Jacobs's suggestion, ${ }^{58}$ commercial uses are associated with

$55 \mathrm{Id}$. The floor area ratio (FAR) is the ratio of total floor area of buildings to the size of the land. In most of Los Angeles, the permitted ratios range from as low as 1.5:1 to a maximum of 13:1. Id. $\S 14 \cdot 5 \cdot 3$.

56 Id. $\S 12.04$.

57 But see Adele V. HARREll \& CATERina Gouvis Roman, COMMUNity DeCAY AND CRIME: ISSUES FOR POLICY RESEARCH 18-20 (1994) (finding that the percentage of lots zoned for commercial use was associated with an increased risk of robbery).

58 See JACOBS, supra note 12 , at 36-37 (theorizing that commercial uses sprinkled among residential areas increase safety because "storekeepers and other small business[people] are typically strong proponents of peace and order themselves" and because increased foot traffic to the commercial uses increases surveillance in the area). 
increased rather than decreased crime. ${ }^{59}$ Similarly, considerable research on this issue has shown that homogeneous residential neighborhoods have lower rates of crime than mixed-use neighborhoods. ${ }^{60}$

What explains the findings that commercial land use is generally associated with more crime? Or, more generally, why does the built environment seem to make a difference? We turn now to some more specific mechanisms by which the built environment and zoning may be linked.

\section{B. Natural Surveillance}

Many have argued that design should "create opportunities for natural surveillance by residents, neighbors, and bystanders." ${ }^{61}$ This concept is an extension of Jane Jacobs's influential theory that "eyes on the street" and general street activity reduce criminal activity. ${ }^{62}$ Routine-activities theory, which is featured prominently in criminology literature, notes the importance

59 See John H. Schweitzer et al., The Impact of the Built Environment on Crime and Fear of Crime in Urban Neighborhoods, J. URB. TECH., Dec. 1999, at 59, 66 (finding the presence of nearby stores associated with increased crime); Thomas D. Stucky \& John R. Ottensmann, Land Use and Violent Crime, 47 CRIMINOLOGY 1223, 1249 (2009) (finding that violent crime and the percentage of land use devoted to commercial activity were generally related, though this finding was conditioned on an area's other socioeconomic characteristics); Ralph B. Taylor et al., Street Blocks with More Nonresidental Land Use Have More Physical Deterioration: Evidence from Baltimore and Philadelphia, 31 URB. AFF. REv. 120, 132 (1995) ("[R]esidential street blocks with more nonresidential land uses have higher crime rates." (citation omitted)).

60 See, e.g., Stephanie W. Greenberg \& William M. Rohe, Neighborhood Design and Crime: A Test of Two Perspectives, 50 J. AM. Plan. Ass'N 48, 53 (1984); Greenberg et al., supra note 16, at 151-54 (finding that low-crime neighborhoods contained fewer major streets and were more likely to have boundaries isolating them from other neighborhoods); Pamela Wilcox et al., Busy Places and Broken Windows? Toward Defining the Role of Physical Structure and Process in Community Crime Models, 45 SOC. Q. 185, 199-200 (2004) (finding that the existence of businesses and playgrounds in a neighborhood increases residential burglaries, but that the effect was mitigated by physical disorder and residential instability); Barbara Dietrick, The Environment and Burglary Victimization in a Metropolitan Suburb (finding residential burglary more frequent near commercial areas), reprinted in 2 AM. INST. FOR RESEARCH, THE LINK BETWEEN CRIME AND THE BUILT ENVIRONMENT: METHOdOlOGICAL REVIEWS OF INDIVIDUAL CRIME-ENVIRONMENT STUdies, at C-33, C-41 (Tetsuro Motoyama et al. eds., 1980); Xiaowen Yang, Exploring the Influence of Environmental Features on Residential Burglary Using Spatial-Temporal Pattern Analysis 99 (2006) (unpublished Ph.D. dissertation, University of Florida), available at http:// gradworks.umi.com/32/24/3224656.html (finding at major street-block and census-block levels that burglaries were more common in mixed-use sites with heterogeneous zoning as compared to matched-control sites with homogeneous zoning).

61 Katyal, supra note 3, at 1048; see also Al ZELINKA \& DEAN BRENNAN, SAFESCAPE: Creating Safer, More livable Communities Through Planning and Design 8, 10-11 (2001) (emphasizing the importance of natural surveillance and illustrating instances in which design can encourage or discourage natural surveillance).

62 See Katyal, supra note 3, at 1050 ("Private individuals are responsible for the majority of crime prevention."). 
of capable guardianship in reducing the propensity of motivated offenders to commit crimes against suitable targets. ${ }^{63}$ Individuals who act as "eyes on the street" and are proactive in calling the police, or asking questions of potential criminals, may be more prevalent in areas where natural surveillance makes the observation of strangers on the street easier. The process by which individuals living in neighborhoods actively intervene in ways that discourage problem behaviors has been termed "collective efficacy." ${ }^{64}$

Some empirical studies are consistent with the claim that natural surveillance is associated with lower crime. Studies of crime on or near mass transit confirm that visibility is important, ${ }^{65}$ and Thomas Molumby found that poor visibility helped predict the locations of crimes in a university housing project. ${ }^{66}$ Indeed, interviews with criminals suggest that they consider visibility when selecting targets. ${ }^{67}$ Convenience stores are often robbed in part because they are located far from the street to make room for parking. This distance hinders visibility and makes them an easy robbery target. ${ }^{68}$

63 See Lawrence E. Cohen \& Marcus Felson, Social Change and Crime Rate Trends: A Routine Activity Approach, 44 AM. SOC. REV. 588, 590 (1979) (arguing that the presence of capable guardians alone is sufficient to prevent crime).

64 See Robert J. Sampson et al., Neighborhoods and Violent Crime: A Multilevel Study of Collective Efficacy, 277 SCIENCE 918, 922 (1997) (finding that "collective efficacy," defined as the level of neighborhood social cohesion and willingness of residents to engage in informal social control activities, is linked to lower rates of crime and violence).

65 See Patricia Mayhew et al., Home Office Research Unit, Crime as OPPORTUNITY 23-24 (1976) (finding that damage to bus seats in London is significantly more prevalent in areas with lower visibility); Richard Block \& Carolyn Rebecca Block, The Bronx and Chicago: Street Robbery in the Environs of Rapid Transit Stations (finding low crime rates in areas immediately adjacent to mass transit in a study of the Bronx and Chicago), in ANALYZING CRIME PATTERnS: Frontiers OF PRACTICE 137, 147-48 (Victor Goldsmith et al. eds., 2000); R. Lance Shotland \& Lynne Goodstein, The Role of Bystanders in Crime Control, 40 J. SOC. ISSUES 9, 18 (1984) (finding that increased ridership on New York subways reduced crime).

66 Thomas Molumby, Patterns of Crime in a University Housing Project, 20 AM. BEHAV. SCIENTIST 247, 256 (1976).

67 See Trevor Bennett \& Richard Wright, Burglars on Burglary: Prevention AND THE OFFENDER 58-62 (1984) (describing a study in which convicted burglars commented on the importance of cover in evaluating potential houses to burglarize); Sally E. Merry, Defensible Space Undefended: Social Factors in Crime Control Through Environmental Design, 16 URB. AFF. Q. 397, 416 (1981) (indicating that robbers prefer locations with "narrow and enclosed pathways where visibility is poor and witnesses [are] non-existent").

68 See C. Ray Jefferr, Crime Prevention Through environmental Design 201, 205 (2d ed. 1977) (finding in a study of convenience store robberies that "lighting, . . . outdoor visibility, . . . and other opportunity structures were related to high robbery rates"); Carri Casteel \& Corinne Peek-Asa, Effectiveness of Crime Prevention Through Environmental Design (CPTED) in Reducing Robberies, 18 AM. J. PREVENTIVE MED. 99, 100, 109 (2000) (summarizing twenty-six published studies generally finding that the adoption of CPTED principles, including increasing visibility into a store, can reduce robberies in convenience stores); see also Dennis C. Duffala, Convenience Stores, Armed Robbery, and Physical Environmental Features, 20 AM. BEHAV. SCIENTIST 
Another study found that a housing project with an elevator lobby visible to the outside had a much lower crime rate than another project without a visible lobby ${ }^{69} \mathrm{~A}$ much stronger experimental study randomly selected sixty convenience stores and increased the visibility of cashiers to passersby through measures like removing signs on windows and increasing lighting; the study found that these stores had significantly fewer robberies in an eight-month follow-up period compared to the sixty control stores with no additional visibility measures. ${ }^{70}$

In theory, land use diversity could also increase natural surveillance by bringing more people to an area. Jacobs waxed rhapsodically about the benefits of mixed-use neighborhoods because varied uses attracted "eyes on the street" to deter crime. ${ }^{71}$ So, for example, she argued that bars should reduce residential crime because they bring people to the neighborhood. ${ }^{72}$ Similarly, one study found that small businesses serve as both "watchers" of their surroundings and as central nodes of communication about crime. ${ }^{73}$

Empirical research has suggested the importance of the watcher's identity. Contrary to Jacobs's hypothesis that bars would reduce crime by increasing street traffic, bars actually tend to increase assaultive behaviors and robberies in neighborhoods. ${ }^{74}$ Moreover, a diversity of uses might make it harder to identify abnormal behaviors or the presence of potentially threatening strangers.

Lighting should also increase natural surveillance, both because it increases visibility and because it encourages more people to congregate in

227, 244-45 (1976) (attributing a convenience store's vulnerability to armed robbery to low vehicular traffic, more sparse commercial activity, and proximity to major transportation routes).

69 See NEWMAN, supra note 16 , at 87 (finding that a housing project with a visible lobby had a crime rate that was $33 \%$ below the New York City average while a building without a visible lobby had a crime rate that was $52 \%$ higher than the New York City average). One limitation of Newman's study was its comparison of only two sites. Thus, it is entirely possible that these differences could have emerged by chance.

70 See Wayman J. Crow \& James L. Bull, Robbery Deterrence: An Applied BEHAVIORAL SCIENCE DEMONSTRATION-FINAL REPORT (1975).

71 See JACOBS, supra note 12, at 56 ("The trust of a city street is formed over time from many, many little public sidewalk contacts. It grows out of people stopping by at the bar for a beer, getting advice from the grocer and giving advice to the newsstand man . ...").

72 See id. at 36-37 (stating that bars and restaurants "give people . . . concrete reasons for using sidewalks on which these enterprises face," which in turn "draw[s] people along the sidewalks past places which have no attractions to public use in themselves").

73 See JoAnna Shapland \& Jon VAGG, Policing BY The Public 23, 70-72 (1988) (describing the "almost unconscious" process of shopkeepers and employees to monitor what occurred outside their buildings).

74 See Dennis W. Roncek \& Ralph Bell, Bars, Blocks, and Crimes, 11 J. EnVTL. Sys. 35, 44 (1981) (finding that "each additional bar on a residential block increases the incidence of index crimes by approximately four crimes"). 
the lighted place. ${ }^{75}$ Many studies have documented the relationship between lighting and crime in different physical contexts. ${ }^{76}$

Devices that attract people can also enhance natural surveillance. Some have suggested that neighborhood features like front porches or farmers' markets decrease crime by bringing more people outdoors. ${ }^{77}$ However, despite the superficial plausibility of this hypothesis, the limited empirical evidence does not support it. ${ }^{78}$

\section{Target-Hardening}

A related strand of research has focused on reducing burglary through target-hardening: making specific targets more difficult to burglarize through building codes mandating security measures like higher quality locks, improved door frames, laminated glass, and motion-activated lighting. ${ }^{79}$ Research comparing changes in burglary rates after introducing new building codes suggests that such interventions can successfully reduce burglary without increasing other property crimes. ${ }^{80}$

75 Katyal, supra note 3, at 1056-57.

76 See Cyril Burt, The Young Delinguent 16o-63 (1925) (attributing increased property offenses to longer periods of darkness in winter months); KATE PAINTER, INST. OF Lighting ENG'RS, A GUIDE FOR CRIME AND DisORDER REDUCTION THROUgh A PUblic Lighting STRATEgY (1999) (finding that lighting reduces crime); Ken PEASE, INST. OF Lighting ENG'RS, LIGHTING AND CRIME 7-8 (1999) (noting the high level of agreement in the research that "targeted increases in street lighting generally have crime reduction effects"); Mary S. Smith, Nat'L Inst. of Justice, Crime Prevention Through EnvironMENTAL DESIGN IN PARKING FACILITIES 3 (1996) (stating that "[1]ighting is universally considered to be the most important security feature in a parking facility"); CRIME PREVENTION Through Housing Design 49 (Paul Stollard ed., 1991) (finding that "40\% of night-time street crime occurs when lighting levels are at 5 lux or below ... [and o]nly $3 \%$ of night-time street crime takes place when the lighting level is above 20 lux"); Sherry Plaster Carter et al., Zoning Out Crime and Improving Community Health in Sarasota, Florida: "Crime Prevention Through Environmental Design," 93 AM. J. PUB. HEALTH 1442, 1444 tbl.1 (2003) (finding that application of CPTED principles, including improved lighting in conjunction with increased police presence, reduced crime in a high-crime neighborhood).

77 Katyal, supra note 3 , at 1057-58.

78 See, e.g., Schweitzer et al., supra note 59, at 69 (finding that front porches are associated with greater crime in a study of Lansing, Michigan).

79 See Katyal, supra note 3, at 1067-68 (noting instances in which British towns and housing projects reduced burgalries through target-hardening policies); John Hoffman, Building Codes Help Reduce Burglary, 46 LAW \& ORD. 149 (1998) (discussing police officers' efforts to change building codes to make housing more difficult to burglarize in Simi Valley, California; Overland Park, Kansas; and Toronto, Ontario).

80 See Ben Vollaard \& Jan C. van Ours, Does Regulation of Built-In Security Reduce Crime?: Evidence from a Natural Experiment, 121 ECON. J. 485, 503 (2011) (finding that a law requiring new homes in the Netherlands to have burglar-proof windows and doors was responsible for a $26 \%$ reduction in burglary). Similarly, empirical research shows that car thefts dropped sharply in 


\section{Territoriality and Permeability}

Jacobs also argued that, to reduce crime, there should be clear differentiation between public and private spaces. ${ }^{81}$ In his highly influential book Defensible Space: Crime Prevention Through Urban Design, Oscar Newman argued that breaking housing up into less anonymous, more manageable units would improve public safety. He marshaled descriptive evidence to support his thesis, including a wealth of statistics on contexts ranging from student housing at St. Lawrence College ${ }^{82}$ to public housing projects in New York City. ${ }^{83}$

Perhaps most dramatically, he compared two adjacent public housing projects in Brooklyn: Brownsville and Van Dyke. While both were similar in terms of density, size, and demographic characteristics, they had very different architectural forms. Brownsville had a more traditional mix of three- to six-story elevator and walk-up buildings. ${ }^{84}$ Van Dyke, in contrast, was comprised of fourteen-story towers with long hallways opening onto elevator banks and fire code-required stairwells. ${ }^{85}$ Between 112 and 136 families shared each doorway leading into Van Dyke. ${ }^{86}$ In contrast, each entryway in Brownsville served only six to eighteen families. ${ }^{87}$ Van Dyke Homes had $66 \%$ more crime incidents than the Brownsville project and far more vandalism. ${ }^{88}$ While the research design was imperfect, ${ }^{89}$ the comparison illustrated the capacity of the built environment to reduce crime by altering territoriality.

countries after auto manufacturers started installing ignition immobilizers and Lojack systems, making it more difficult to steal cars and avoid detection. Philip J. Cook \& John MacDonald, The Role of Private Action in Controlling Crime, in CONTROLling CRIME: STRATEGIES AND TRADEOFFS 331, 343-45 (Philip J. Cook et al. eds., 2011).

81 See JACOBS, supra note 12 , at 35 (stating that, to improve safety, "[p]ublic and private spaces cannot ooze into each other as they do typically in suburban settings or in projects.")

82 See NEWMAN, supra note 16, at 75-77 (chronicling higher rates of problems with students living in newer dormitories with numerous individual rooms located along long hallways, as compared to those living in older dormitories divided into separate, smaller buildings with fewer rooms opening off more entryways).

83 See id. at 69 (finding four-and-a-half crimes per thousand persons in hallways with two to five apartments as compared to more than eight crimes per thousand persons in hallways with six or more apartments).

$84 \mathrm{Id}$. at 40.

85 Id. at $40-43$.

$86 \mathrm{Id}$. at 41 .

87 Id. at 43 .

88 Id. at $47-48$.

89 Since the basis of comparison involved only two complexes, these differences could stem from simple chance or result from differences in the tenants chosen to live in each building type. One can imagine that the Brownsville design was a more desirable living environment and therefore attracted tenants who were less likely to be crime perpetrators and victims. 
From his study, Newman concluded that the physical environment should "create perceived zones of territorial influence: mechanisms for the subdivision and articulation of areas of the residential environment intended to reinforce inhabitants in their ability to assume territorial attitudes and prerogatives." 90

Katyal expounded on this argument: "Territoriality connotes ownership or stewardship of an area. It both provides an incentive for residents to take care of and to monitor an area and subtly deters offenders by warning them that they are about to enter a private space." 91

Both Newman and Katyal note the relationship between territoriality and surveillance. Katyal explains: "Concern about territoriality should be balanced against the need for natural surveillance, so that spaces are neither too open nor too closed. If they are too closed, bystanders and residents cannot self-police; if they are too open, intrusion and crime could increase."92 Newman likewise comments that "improving visual surveillance opportunities may be a pointless task if the resident is viewing activity taking place in an area he does not identify with." 93 Similarly, another commentator has noted that communities that are too permeable can lead to a decrease in community social cohesion or "social cocooning." 94

Some empirical support exists for Newman's territoriality theory, as several studies have found that markers of territoriality are associated with lower crime. ${ }^{95}$ One study, however, noted that territorial displays are seen

90 NEWMAN, supra note 16 , at 50.

91 Katyal supra note 3, at 1058-59; see also AliCE COLEMAN, UTOPIA ON TRIAL: VisiON AND REALITY IN PLANNED HOUSING 138-39 (1985) (suggesting that crime could be reduced by physically limiting site accessibility and by demarcating private and public space). One earlier study also noted that territoriality provided a disincentive to burglars. After classifying territory as primary, secondary, or public territory, Barbara Brown and Irwin Altman suggested that burglars would reassess criminal prospects as they crossed territorial boundaries. See Barbara B. Brown \& Irwin Altman, Territoriality and Residential Crime: A Conceptual Framework, in ENVIRONMENTAL CRIMINOLOGY 64-67 (Paul J. Brantingham \& Patricia L. Brantingham eds., 1981).

92 Katyal, supra note 3, at 1059.

93 NEWMAN, supra note 16 , at 50.

94 Ralph B. TAYlor \& Adele V. Harrell, Nat'l Inst. of Justice, Physical ENVIRONMENT AND CRIME 12-13 (1996) (noting that nonresidential land use and traffic can diminish residents' sense of community); see also DONALD APPLEYARD, LIVABLE STREETS 9 (1981) (claiming that increased traffic on city streets reduces social cohesion); Andrew Baum et al., Crowding and Neighborhood Mediation of Urban Density, 1 J. POPULATION 266, 276 (1978) (claiming that stores on a street reduce interaction among residents because more "unfamiliar" people use the street to visit stores).

95 See, e.g., Ralph B. Taylor et al., User-Generated Visual Features as Signs in the Urban Residential Environment (finding that personalizations are perceived as signs that neighborhoods are safe), in 1 THE Behavioral BASIS OF DESIGN 94, 94-10o (L.M. Ward et al. eds., 1976); Sidney Brower et al., Residents' Perceptions of Territorial Features and Perceived Local Threat, 15 ENV'T \& BEHAV. 
as less effective deterrents when the perceived threat rises. ${ }^{96}$ Another study concluded that physical permeability matters more than markers of informal territorial control. ${ }^{97}$

Considerable evidence links more neighborhood permeability with higher crime. ${ }^{98}$ Studies find that houses built on culs-de-sac have lower rates of burglary than houses on through-traffic streets, even after statistically controlling for the level of vacant housing, unemployment rate, age composition, and other factors in the surrounding census area. ${ }^{99}$ Similarly, houses farther from highway exits, on dead-end streets, and not on corners are less likely to be burglarized. ${ }^{100}$

Moreover, a number of studies have found that street closures are effective in reducing some kinds of crime. ${ }^{101}$ Interestingly, however, gated

419, 434 (1983) (finding that gardens or other plants are "territorial sign[s]" that reduce trespassing and other crime); Barbara B. Brown, Residential Territories: Cues to Burglary Vulnerability, 2 J. ARChitectual \& Plan. RES. 231, 234-35 (1985) (finding that houses in Salt Lake County, Utah, with nameplates have lower rates of intrusion than those without nameplates); Ralph B. Taylor et al., Block Crime and Fear: Defensible Space, Local Social Ties, and Territorial Functioning, 21 J. RES. CRIME \& DELINQ. 303, 306 fig.1 (1984) (proposing that defensible space features and local social ties reduced crime and fear both directly and indirectly through territorial functioning); see also Ralph B. Taylor \& Stephen Gottfredson, Environmental Design, Crime, and Prevention: An Examination of Community Dynamics, 8 CRIME \& JUST. 387, 411 (1986) (reviewing literature to conclude that "simple effects of physical environment on crime range from small to moderate").

96 Brower et al., supra note 95, at 430.

97 See Greenberg et al., supra note 16 , at $162-63$ (basing its conclusion on a comparison of three pairs of matched neighborhoods in Atlanta, Georgia).

98 See, e.g., Carol Bevis \& Julia Brown Nutter, Minn. Crime Prevention Ctr., Changing StreEt LAYOUTS TO REDUCE RESIDENTIAL BuRglarY 22 (1977) ("Inaccessible street layouts are associated with low residential burglary rates."); Garland F. White, Neighborhood Permeability and Burglary Rates, 7 JUST. Q. 57, 64 (1990) (finding that permeability is positively correlated with higher burglary); Yang, supra note 6o, at 138-39 (noting that burglary in Gainesville, Florida, was associated with every measure of permeability, including proximity to major roads, distance to public transportation, block length, gridiron street patterns, and location on through-traffic streets); see also Paul Cozens \& Terence Love, Manipulating Permeability as a Process for Controlling Crime: Balancing Security and Sustainability in Local Contexts, 35 BUILT ENV'T 346, 360 (2009) (recommending that street permeability be manipulated at the local level to reduce crime rates).

99 See, e.g., Shane D. Johnson \& Kate J. Bowers, Permeability and Burglary Risk: Are Cul-deSacs Safer?, 26 J. QuANTITATIVE CRIMINOLOGY 89, 109 tbl.5 (2010) (collecting studies that show that increased permeability is associated with increased risk of burglary).

100 Simon Hakim et al., Target Search of Burglars: A Revised Economic Model, 80 PAPERS REgiONAL SCI. 121, 130-31 (2001); see also George Rengert \& Simon Hakim, Burglary in Affluent Communities: A Planning Perspective (showing that the houses with the highest burglary rates are houses on busy residential streets or on back roads), in REDUCING CRIME THROUGH REAL Estate Development And Management 39, 46 figs.33-34 (Marcus Felson \& Richard B. Peiser eds., 1998).

101 See James Lasley, Nat'L Inst. Of Justice, "Designing Out” Gang Homicides AND STREET ASSAULTS 1 (1998) (finding that creating culs-de-sac reduced serious homicides and 
communities do not appear to exhibit lower crime rates than similar nongated communities. ${ }^{102}$

Another important aspect of territoriality is to limit the number of people using particular common areas. Some scholars, for example, have suggested that entryways limited to six to twelve families create increased territoriality. ${ }^{103}$ Smaller groups are also more likely to "cognitively recognize" and informally influence their neighbors, which connects to the theoretical concept of "collective efficacy."104

The repeated finding that commercial land uses are associated with more crime may result because commercial land uses reduce territoriality and informal social control of residents. ${ }^{105}$ Residents in an area with nonresidential uses are less happy, ${ }^{106}$ less likely to have contact with their neighbors, ${ }^{107}$ and less likely to be able to distinguish local residents and outsiders. ${ }^{108}$

There is also a relationship between territoriality and natural surveillance. Others have suggested that, without sufficient density, commercial strips (in contrast to higher-density commercial areas) might be associated with crime because the linearity of the commercial strip reduces activity and

assaults in an experimental area of a Los Angeles neighborhood); Roger Matthews, Developing More Effective Strategies for Curbing Prostitution (finding a reduction in street prostitution following closures of streets), in SituATIONAL CRIME PREvEnTIOn: SUCCESsful CASE STUdies, 74, 78-79 (Ronald V. Clarke ed., 2d ed., 1997).

102 See EdWARD J. Blakely \& MARy Gail SNyder, Fortress AmERicA: GATEd COMmUNities IN THE UNITED STATES 128 (1997) (finding that, "although people may feel safer, they probably are not significantly safer" in gated communities).

103 See, e.g., Paul Stollard, Crime Prevention Through Housing Design 57 (1991) ("The use of common entrances should be avoided wherever possible and invidual flat entrances should ideally be located at ground level.").

104 ERving Goffman, BeHavior in Public Places: Notes on THE Social ORGANIZATION OF GATHERING 112-113, 132-34 (1963); see also Sampson et al., supra note 64, at 919 (" $[\mathrm{S}]$ ocially cohesive neighborhoods will prove the most fertile contexts for the realization of informal social control.").

105 See, e.g., Garnett, The People Paradox, supra note 3, at 46-47 (summarizing research finding that "suburban communities are more socially cohesive and their residents more socially involved than urban communities and urbanites").

106 See Baum, supra note 94, at 276 (attributing the difference in happiness between residents of areas with nonresidential land use and only residential land use to how often they must interact with "unfamiliar others").

107 See id. ("They seemed to withdraw, avoiding neighbors and outdoor areas interaction was likely."); see also APPLEYARD, supra note 94, at 245 (noting that many people wish to escape from "crowded conditions").

108 See Brown \& Altman, supra note 91, at 55 (claiming that nonresidential land use diminishes residents' capability to survey spaces in their environment); Greenberg et al., supra note 16, at 61 ("Relative to high crime neighborhoods, the flow of outsiders into and out of lower crime neighborhoods appeared to have been limited by more homogeneous residential land use."); Taylor et al., supra note 59, at 131 (finding that "resident-based informal control is weaker on blocks that are less homogeneously residential"). 
eyes on the street. ${ }^{109}$ Similarly, some have argued that nonresidential uses may be associated with increased crime because those uses create holes in the fabric of the community, attract outsiders, and generally impair the facial recognition of those who belong in the neighborhood. ${ }^{110}$

Another study focused on land use in sixty street blocks in Philadelphia and compared stores with other nonresidential land use. ${ }^{111}$ The study found that nonresidential land use of all kinds decreased social ties and surveillance. ${ }^{12}$ Storefront land use was associated with more calls for police service, but most of the calls were not crime-related. ${ }^{113}$ The study also found more physical disorder in certain nonresidential areas. ${ }^{114}$

\section{E. Physical Disorder}

Another aspect of the relationship between the built environment and crime is the relationship between physical disorder and crime. James Wilson and George Kelling's famous "broken windows" hypothesis suggested that physical disorder could act as a signal to criminals about the lack of social investment in a community and could lead to increased crime. ${ }^{115}$ But the

109 See Angel, supra note 14 (manuscript at 16) (describing how crime is reduced as the number of people on a street increases because "not enough potential victims are present and the likeliness of a rewarding opportunity is small”).

110 See Ralph B. Taylor \& Sidney Brower, Home and Near-Home Territories (noting that residents of a homogeneous block were more likely than residents of a mixed-use block to react to recent crime by creating informal patrol groups), in 8 HOME ENVTS. 183, 201-02 (Irwin Altman \& Carol M. Werner eds., 1985); Taylor et al., supra note 95, at 317 (providing the results of a study that "confirms the notion that informal social control may directly reduce crime-related outcomes”); Ralph B. Taylor et al., Territorial Cognitions and Social Climate in Urban Neighborhoods, 2 BASIC \& APPLIED SOC. PSYCHOL. 289, 292 (1981) (hypothesizing that "as perceived homogeneity [in a neighborhood] increases, problems may decrease, insider/stranger distinctions may be easier, and responsibility may increase");

111 Ellen M. Kurtz et al., Land Use, Physical Deterioration, Resident-Based Control and Calls for Service on Urban Streetblocks, 15 JUST. Q. 121 (1998).

$112 I d$. at 146.

113 Id. at $146-47$.

114 Id. at 146 (finding that "blocks with more viable storefronts" are likely to lead to deterioration, but that other nonresidential uses do not predict disorder).

115 James Q. Wilson \& George L. Kelling, Broken Windows, Atlantic Monthly, Mar. 1982, at 29, 31; see also GEORGE L. KELling \& William H. SOUSA, JR., MANHATtAn Inst. CTR. FOR CIVIC INNOVATION, NO. 22, DO POLICE MATTER? AN ANALYSIS OF THE IMPACT OF NEW YORK CITY'S POLICE REFORMS 18 (2001) ("One singularly important way [police can reduce crime] is by restoring and maintaining order, through 'broken windows' policing."). But see Bernard E. Harcourt \& Jens Ludwig, Broken Windows: New Evidence from New York City and a Five-City Social Experiment, 73 U. CHI. L. REV. 271, 292-93 (2006) (re-analyzing Kelling and Sousa's conclusion that order-maintenance policing led to a drop in crime and explaining that the study failed to consider that drug prevention may have affected these results). Dan Kahan argues that order-maintenance policing has a positive social impact and reduces crime by creating a social 
precise relationship between physical disorder and crime (if any) remains unclear. ${ }^{116}$

There have been several studies attempting to test this hypothesis. One empirical study suggested that a crime feedback loop exists in which weak neighborhood social cohesion leads to crime and disorder, which in turn leads to increased fear. ${ }^{117}$ This increased fear further weakens neighborhood cohesion.

Robert Sampson and Stephen Raudenbush conducted a careful crosssectional study that controlled for collective efficacy, land use, and some other measures. ${ }^{118}$ They found no effect of observed physical disorder in neighborhoods on the probability that respondents living in these neighborhoods reported a violent victimization, a household burglary, or theft in the past six months. ${ }^{119}$

Others have looked at various forms of minor social disorder, which is often lumped with physical disorder in discussions of order-maintenance policing, and considered whether they have an effect on crime. For example, a study of data collected in New York City and a randomized five-city experiment of police foot patrol revealed that targeting minor crimes did not reduce more serious crime. ${ }^{120}$

The role of land use in affecting disorder also remains unclear. One study of one hundred Seattle census blocks concluded that land use affected physical disorder, which in turn affected crime. ${ }^{121}$ However, the effect of land use on crime was complex. For example, while businesses seemed to increase physical disorder, they also seemed to decrease burglary. Businesses

"perception of obedience to law." Dan M. Kahan, Social Influence, Social Meaning, and Deterrence, 83 VA. L. REV. 349, 367-73; see also Dan M. Kahan, Reciprocity, Collective Action, and Community Policing, 90 CALIF. L. REV. 1513, 1527-38 (2002) ("[T]he theory behind order-maintenance policing is that visible disorder undermines law-abiding norms.”).

116 See Wilcox et al., supra note 6o, at 185-90.

117 Fred Markowitz et al., Extending Social Disorganization Theory: Modeling the Relationship between Cohesion, Disorder, and Fear, 39 CRIMINOLOGY 293, 314 (2001).

118 Robert J. Sampson \& Stephen W. Raudenbush, Systematic Social Observation of Public Spaces: A New Look at Disorder in Urban Neighborhoods, 105 AM. J. SOC. 603, 603-609 (1999); see also id. at 637 (finding greater social and physical disorder with mixed land use and no relationship between public disorder and crime except for robbery). Sampson and Raudenbush also noted that past studies that found a relationship between physical disorder and crime had methodological problems, as those studies were based on neighborhood surveys that asked residents about both disorder and crime. $I d$. at 606.

$119 \mathrm{Id}$.

120 Harcourt \& Ludwig, supra note 115, at 287-97; see also Jeffrey A. Fagan \& Garth Davies, Policing Guns: Order Maintenance and Crime Control in New York (finding no relation between stopand-frisk activity and crime, except among Hispanics), in GUNS, CRIME AND PUNISHMENT IN AMERICA 191, 205 tbl.9.3 (Bernard E. Harcourt ed., 2003).

121 Wilcox et al., supra note 6o, at 201. 
in unstable areas reduced burglary more than businesses in more stable neighborhoods. ${ }^{122}$ Another study found that street blocks with more nonresidential land uses had higher levels of physical deterioration: The authors hypothesized that " $r$ r]esidential blocks with more nonresidential land uses may have more incivilities because the uses draw more people to the block and/or because the uses interfere with resident-based territorial functioning." ${ }^{23}$ In other words, commercial uses create disorder by impeding territorial functioning that would normally occur in residential areas. Nonetheless, these studies suffer from design limitations because the authors cannot isolate and measure the effects of land use from existing differences between areas.

Another study, with a stronger design, ${ }^{124}$ was based on repeated observations of neighborhoods in Baltimore. ${ }^{125}$ It found that "crime causes later grime" - that there was an association between physical disorder and crime but that the causal arrow led from crime to physical disorder rather than the other way. ${ }^{126}$

Finally, a team of Dutch researchers used a field experiment and found strong evidence that disorder tends to encourage other forms of disorder. ${ }^{127}$ The researchers conducted six similar experiments and found that when the amount of graffiti increased, the level of littering and likelihood that people would steal a five-euro note also increased. ${ }^{128}$ Similarly, the presence of unreturned shopping carts increased littering. ${ }^{129}$ The study also discovered that having bicycles illegally locked to a fence increased the likelihood that people would trespass by taking a shortcut. ${ }^{130}$ While these results are suggestive, it is unclear whether they also apply to serious crimes, especially those that involve direct personal victimization.

122 Id

123 Taylor et al., supra note 59, at 120. Different nonresidential land uses, however, may have different effects. Id. at 13o. For example, an industrial area, a school, a church, and a commercial area may each generate very different traffic patterns and cause different effects.

124 We use the term "stronger" because the design of this study, by focusing on repeated observations, mitigates the problem of stable differences between areas skewing the results.

125 RALPH B. TAYLOR, BREAKING AWAY FROM BROKEN WindOWS: BALTIMORE Neighborhoods AND THE NATIONWIDE FIgHT AgAinst CRIME, GRIME, FEAR, AND DECLINE (Hugh D. Barlow ed., 2000).

126 Id. at 171-72.

127 See Kees Keizer et al., The Spreading of Disorder, 322 SCIENCE 1681, 1684 (2008) ("[A]s certain norm-violating behavior becomes more common, it will negatively influence conformity to other norms and rules.").

128 Id. at $1683-84$.

$129 \mathrm{Id}$. at 1684 .

130 Id. at $1683-84$. 


\section{F. Crime Attractors/Reducers}

Another strand of the literature focuses less on a global causal mechanism and instead on specific land uses that are associated with increased or decreased crime. Jacobs, for example, hypothesized that parking lots, truck depots, and gas stations were harmful for city life ${ }^{131}$ but that bars and restaurants would reduce crime.

Empirical research, however, has found that bars are, in fact, associated with increased crime. ${ }^{132}$ Other studies have found that particular kinds of crime are positively associated with institutional land ownership, ${ }^{133}$ public high schools, ${ }^{134}$ vacant lots, ${ }^{135}$ fast-food restaurants, ${ }^{136}$ and alcohol outlets. ${ }^{137}$

Other research has charted the relationship between specific types of land use and particular kinds of crime. For example, one study found that

131 JACOBS, supra note 12, at 234 .

132 See Dennis W. Roncek \& Pamela A. Maier, Bars, Blocks, and Crimes Revisited: Linking the Theory of Routine Activities to the Empiricism of "Hot Spots," 29 CRIMINOLOGY 725, 738 (1991); Dennis W. Roncek \& Mitchell A. Pravatiner, Additional Evidence That Taverns Enhance Nearby Crime, 73 SOC. \& SoC. RES. 185, 186 (1989).

133 David Ley \& Roman Cybriwsky, The Spatial Ecology of Stripped Cars, 6 ENV'T \& BEHAV. $53,61(1974)$.

134 See Dennis W. Roncek \& Donald Faggianni, High Schools and Crime: A Replication, 26 SOC. Q. 491, 501-02 (1985); Dennis W. Roncek \& Antoinette LoBosco, The Effect of High Schools on Crime in Their Neighborhoods, 64 SoC. SCI. Q. 598, 606 tbl.3 (1983); Caterina Gouvis Roman, Schools as Generators of Crime: Routine Activities and the Sociology of Place 91-93 (Dec. 6, 2002) (unpublished Ph.D. dissertation, American University), available at http://www.ncjrs.gov/ pdffiles1/nij/grants/201946.pdf. But see Margaret F. Brinig \& Nicole Stelle Garnett, Catholic Schools and Broken Windows, 9 J. EMP. L. STUD. 347, 365-66 (2012) (finding that neighborhoods that experienced closures of local Catholic schools experienced less decrease in crime than other neighborhoods and suggesting social capital as the most plausible explanation).

135 See Dennis C. Duffala, Convenience Stores, Armed Robbery, and Physical Environment Features, 20 AM. BEHAV. SCIENTIST 227, 239 (1976) (suggesting that stores near vacant lots are more vulnerable to armed robbery than are stores near commercial lots).

136 Patricia L. Brantingham \& Paul J. Brantingham, Mobility, Notoriety, and Crime: A Study of Crime Patterns in Urban Nodal Points, 11 J. ENVTL. SYS. 89 (1982).

137 See, e.g., Dennis M. Gorman et al., Spatial Dynamics of Alcohol Availability, Neighborhood Structure and Violent Crime, 62 J. STUD. AlCOHOL 628, 634 (2001); Richard A. Scribner, et al., The Risk of Assaultive Violence and Alcohol Availability in Los Angeles County, 85 AM. J. PUB. HEAlth 335, 338 (1995); Paul W. Speer et al., Violent Crime and Alcohol Availability: Relationships in an Urban Community, 19 J. PUB. HEALTH POL'Y 303, 311 (1998); Richard J. Stevenson et al., The Relationship Between Alcohol Sales and Assault in New South Wales, Australia, 94 ADDICTION 397, 407 (1999); L. Zhu et al., Alcohol Outlet Density and Violence: A Geospatial Analysis, 39 Alcohol \& Alcoholism 369, 372 (2004); Richard Scribner et al., Alcohol Availability and Homicide in New Orleans: Conceptual Considerations for Small Area Analysis of the Effect of Alcohol Outlet Density, 6o J. STud. Alcohol 310, 314-15 (1999); William Alex Pridemore \& Tony H. Grubesic, Alcohol Outlets and Community Levels of Interpersonal Violence: Spatial Density, Outlet Type, and Seriousness of Assault, J. RES. CRIME \& DELINQ. (May 17, 2011), http://jrc.sagepub.com/ content/early/2011/04/15/0022427810397952. 
street robberies were most strongly associated with the number of nearby hotels and motels. ${ }^{138}$ The same study found that other land uses-including bars, restaurants, gas stations, and parking lots-were more weakly associated with street robberies. ${ }^{139}$ In one study of Seattle, the presence of playgrounds decreased violent crime in highly unstable neighborhoods, contrary to the authors' expectations. ${ }^{140}$ However, playgrounds were also correlated with increased burglaries. ${ }^{141}$ William McCarty found that mobile-home communities in Omaha, Nebraska, were not associated with increased crime compared to other kinds of residential communities. ${ }^{142}$ Another line of studies discovered higher crime rates in blocks with public housing projects. ${ }^{143}$ In addition, one study found that higher rates of home foreclosure contributed to higher crime rates. ${ }^{144}$

One particularly strong empirical study of the association between the presence of alcohol outlets and crime rates avoided many of the selectionbias problems previously noted. The study compared the crime rates in places before alcohol outlets opened or closed to the rates in places where alcohol outlets stayed open. Because alcohol outlets operated in both locations (where outlets opened or closed and where outlets stayed open), this method reduces an important source of selection bias. The study found that the opening of alcohol outlets in low socioeconomic neighborhoods affected crime rates. ${ }^{145}$

138 William R. Smith et al., Furthering the Integration of Routine Activity and Social Disorganization Theories: Small Units of Analysis and the Study of Street Robbery as a Diffusion Process, 38 CRIMINOLOGY 489, 507 (2000).

139 See id.

140 Wilcox et al., supra note 6o, at 199.

141 See id. ("In contrast to violent crime findings, presence of playgrounds was positively associated to burglary.”).

142 See William P. McCarty, Trailers and Trouble? An Examination of Crime in Mobile Home Communities, 12 CITYSCAPE: J. POL'Y DEV. \& RES. 127, 136-37 (2010).

143 See Terence Dunworth \& Aaron SAiger, NAT'L Inst. of Justice, Drugs AND CRime in Public Housing: A Three-City ANAlysis 36-37 (1994) (finding higher rates of reported violent crime in areas with housing projects than rates in nearby neighboorhoods in Washington, D.C.; Los Angeles, California; and Phoenix, Arizona); Thomas L. McNulty \& Steven R. Holloway, Race, Crime, and Public Housing in Atlanta: Testing a Conditional Effect Hypothesis, 79 SOC. FORCES 707, 722 (2000) (finding an association between higher crime rates and predominantly Black neighborhoods when the neighborhoods are in close proximity to public housing); Dennis W. Roncek et al., Housing Projects and Crime: Testing a Proximity Hypothesis, 29 SOC. PROBS. 151, 157 (1981) (finding crime rates higher on blocks with housing projects).

144 See Michael Bess, Assessing the Impact of Home Foreclosures in Charlotte Neighborhoods, GEOGRAPHY \& PUB. SAFETy, Oct. 2008, at 2, 3 (2008).

145 See Bing-ru Teh, Essays on Crime and Urban Economics 22 (Spring 2008) (unpublished Ph.D. dissertation, University of California, Berkeley). 
Research has also noted that crime is not evenly distributed and instead clusters in crime "hot spots." While not specifically focused on land use, a seminal paper analyzed police-call data in Minneapolis and found hot spots in commercial establishments - namely, a department store, a discount store, a convenience store, and a bar. ${ }^{146}$

Finally, there has been some research on crime reducers-institutions that may be effective at reducing neighborhood crime. One study concluded that Catholic schools appeared to reduce crime and found that Catholicschool closures are associated with a relative increase in crime. ${ }^{147}$ MacDonald et al. found that business improvement districts (BIDs) - organizations created by property owners to provide public goods-reduced robberies and other violent crimes in Los Angeles. ${ }^{148}$ Finally, some research suggests that more vegetation is associated with less crime ${ }^{149}$ and fear of crime. ${ }^{150}$

\section{G. Density}

Land use law can also affect commercial and residential density, but density's effect on crime has not been thoroughly researched. A recent study of Columbus, Ohio, found interesting curvilinear relationships between density and rates of aggravated assault and homicide. ${ }^{151}$ At low levels of aggregation (blocks), increases in density were associated with increases in these crimes. ${ }^{152}$ At larger geographic levels of analysis, however, increases in commercial and residential densities were associated with reductions in these crimes. ${ }^{153}$ Other studies have found that density was not associated with higher crime when the socioeconomic status of the residents was added

146 See Lawrence Sherman et al., Hot Spots of Predatory Crime: Routine Activities and the Criminology of Place, 27 CRIMINOLOGY 27, 45 tbl.5 (1989).

147 Brinig \& Garnett, supra note 134 , at 366.

148 John MacDonald et al., The Effect of Business Improvement Districts on the Incidence of Violent Crimes, 16 InJ. PREvention 327, 331 (2010); see also Philip J. Cook \& John MacDonald, Public Safety through Private Action: An Economic Assessment of BIDs, 121 ECON. J. 445, 453 (2011) ("The introduction of BIDs is associated with roughly 28 fewer total serious crimes per neighborhood.").

149 Frances E. Kuo \& William C. Sullivan, Environment and Crime in the Inner City: Does Vegetation Reduce Crime?, 33 ENV'T \& BEHAV. 343, 346 (2001).

150 See Irus Braverman, Governing Certain Things: The Regulation of Street Trees in Four North American Cities, 22 TUL. ENVTL. L.J. 35, 47 (2008) (suggesting a negative correlation between the amount of trees and vegetation and the level of fear of crime).

151 Christopher R. Browning et al., Commercial Density, Residential Concentration, and Crime: Land Use Patterns and Violence in Neighborhood Context, 47 J. RES. CRIME \& DELINQ. 329, 343-50 (2010).

$152 I d$. at 343 .

153 Id. The authors also found that, unlike homicide and aggravated assault, robbery was consistently positively associated with density at all levels. Id. at 344 . 
as a controlling variable. ${ }^{154}$ While the empirical literature points to potential relationships between zoning density and crime, the mechanisms for explaining the association have not been rigorously assessed.

\section{H. Limits to Existing Research}

As described above, considerable literature analyzes the relationships between land use, the built environment, and crime-both theoretically and empirically. However, a key problem with existing research is that it has been, with a few notable exceptions, ${ }^{155}$ nonexperimental and based simply on examining cross-sectional correlations. While these studies are useful, they do not support strong conclusions about the causes of crime, because they have not shown whether the particular land use is causing crime or whether there is another factor that may be causing both the observed land use and the crime.

There are a number of high-quality quasi-experimental studies that examine changes in crime levels subsequent to alterations in the physical environment resulting from the establishment of business improvement districts, modifications to building codes, and the closing of schools, roadways, and liquor stores. ${ }^{156}$ But these studies do not specifically examine alterations in the built environment caused by land use zoning. The dearth of rigorous empirical studies on land use zoning types raises the concern that some of the findings reported in the literature are artifacts of selection bias. For example, we may need to reconsider the simultaneous relationships between different land use types and crime as a result of a similar underlying condition, such as poverty concentration. Individuals living below

154 See Yang, supra note 6o, at 102 (finding a correlation between low density and burglary cases); Jianling Li \& Jack Rainwater, The Real Picture of Land Use Density and Crime: A GIS Application, ESRI, http://proceedings.esri.com/library/userconf/procoo/professional/papers/PAP $508 /$ p508.htm (last visited Jan. 11, 2013) (presenting the results of an Irving, Texas, study finding that high density and multi-family development were not necessarily associated with higher crime, although low socioeconomic status was so associated). While not specifically analyzing crime, Ronald Lafferty and H.E. Frech found that increases in non-single family land uses raised property values when sufficiently concentrated. When dispersed, however, the non-single family land uses reduced property values. Ronald N. Lafferty \& H.E. Frech III, Community Environment and the Market Value of Single-Family Homes: The Effect of the Dispersion of Land Uses, 21 J.L. \& ECON. 381, 382, 387-88 (1978).

155 See, e.g., CROW \& BULL, supra note 70, at 74-92 (using an experimental design to show that modifications in the physical environments of convenience stores reduce robberies); Keizer et al., supra note 127 (using an empirical design to show that physical disorder appears to lead to additional physical disorder and minor law-breaking, such as littering and trespassing, but leaving open whether physical disorder leads to more serious forms of crime).

156 See Vollaard \& van Ours, supra note 80, at 16 (building codes); Cook \& MacDonald, supra note 148 , at $453-54$ (BIDs). 
the poverty line have fewer choices about the neighborhoods in which they can live and, as a result, they select into different land use mixes than more affluent households.

Determining the direction of causality may also be difficult. For example, a change in the crime rate can lead to changes in land use if policymakers or landowners perceive that areas should undergo redevelopment. In this case, it may be that the change in crime rate causes the change in land use rather than the reverse.

Similarly, policymakers may simultaneously change multiple factors that may, in turn, affect crime. Suppose, for example, that policing increases at the same time that land use changes. If there is a subsequent change in crime, it is difficult to determine whether the change in policing or land use is responsible. The lack of rigorous research designs limits the extent to which we understand how, if at all, land use affects crime.

In short, land use regulations likely affect crime via the built environment through a number of plausible mechanisms, but there is a limited understanding of the specific micro-level details of these relationships and how public-health law could improve land use policies in communities most affected by crime. Moreover, while we have several quasi-experimental examinations of how alterations of land use can affect crime, most of these alterations are not directly tied to zoning law itself. ${ }^{157}$ As a result, we have plenty of clues but we lack rigorous empirical research identifying how modifying land use through zoning laws can influence crime. As we explain in the next Part, by focusing on zoning-which changes infrequentlyrather than on actual land use, we are able to overcome some of these methodological obstacles.

\section{EMPIRICAL ANALYSIS OF THE EFFECT OF LAND USE LAW ON THE BUILT ENVIRONMENT AND CRIME}

The core research question in this Article is whether there exists a relationship between land use zoning and crime, and if so, whether it is observed through visible differences in the built environment. In this Part, we attempt to answer this question in three steps. First, we examine the association between crime and the primary zoning of parcels of land on street blocks within the same geographic areas of the city. Second, we examine the associations between the primary zoning of parcels of land on

157 These studies do not assess the overall relationship between land use zoning and crime because they are specific to special building provisions or BIDs. See Vollaard \& van Ours, supra note 80 , at 485-87 (modifications of building provisions); see also MacDonald et al., supra note 148, at 329-31 (establishment of BIDs). 
street blocks and physical order maintenance, territoriality, natural surveillance, and "walkability." Finally, we examine whether the observed association between land use zoning of parcels and crime is mediated by differences in the built environment. This will help ascertain whether land use law affects crime through the built environment or whether some other causal mechanism is at work.

Our general strategy in this study is to compare the crime rates on and around street blocks with different types of parcel zoning but within the same geographic areas in Los Angeles. Block-to-block comparisons in the same sections of the city reduce the risk that unobserved confounding variables (e.g., demographic differences) will bias the results. ${ }^{158}$ While this method helps control for many potential confounding variables, it is possible that some unobserved variables remain that are correlated with both zoning and crime. We are, however, unable to identify any particularly plausible candidates that would affect both crime and zoning at a block-byblock level of analysis within the same sections of a city having a comparable demographic makeup. Zoning changes may be requested by property owners, or as part of a comprehensive redevelopment project, but they require considerable effort and are relatively uncommon. ${ }^{159}$ Because of the relative infrequency of zoning changes, the likelihood of reverse causation is low (i.e., crime causing zoning changes).

One alternative avenue of research, which we did not pursue, involves examining the actual land use rather than the zoning classification of parcels. We decided to use zoning classifications for several reasons. First, changing the zoning of a parcel is easier than changing its actual use. Policymakers can, for example, change zoning by passing a new ordinance. Our focus on zoning thus acknowledges it as a tool within the reach of policymakers. Second, zoning evolves more slowly over time than does land use. Zoning is, therefore, less likely to be affected by crime than actual land use, making our inference stronger. If we examined the effect of actual land use on crime, it would be more difficult to determine whether land use affects crime, or whether crime affects changes in land use.

158 We use zoning variations among street blocks as our primary identification strategy. See JOSHUA D. ANGRIST \& JÖRN-STEFFEn PISCHKE, MOSTLY HARMLESS ECONOMETRICS 78 (2009) (describing an identification strategy as an analytic method which permits the researcher to use observational data in a way that approximates a randomized experiment).

159 The city of Los Angeles changed zoning designations for only 361 parcels from 2006 to 2010. See infra text accompanying notes 216-22. 


\section{A. Sample Construction}

For our study, we selected 205 face blocks ${ }^{160}$ in eight Community Plan Areas in Los Angeles. ${ }^{161}$ Table 1 below displays the number of blocks in each area. We chose these areas because they have medium or high levels of crime relative to other sections of the city. ${ }^{162}$ The 205 blocks were selected based on the following criteria: (1) primary and mix of parcel zoning on observed block; (2) primary and mix of parcel zoning on nearby blocks; (3) proximity to parks, schools, Metro (rail) stations, and freeway on-ramps; and (4) geographical severance of block face by roadway (freeway). ${ }^{163}$

Table 1: Number of Street Blocks in Community Planning Areas

\begin{tabular}{lcc}
\multicolumn{1}{c}{ Area Name } & Number of blocks & Percentage of total \\
\hline \hline Boyle Heights & 25 & $12.2 \%$ \\
Highland Park & 30 & $14.6 \%$ \\
Hollywood & 16 & $7.8 \%$ \\
San Pedro & 22 & $10.7 \%$ \\
South Los Angeles & 38 & $18.5 \%$ \\
Southeast Los Angeles & 33 & $16.1 \%$ \\
West Adams & 20 & $9.8 \%$ \\
Westlake & 21 & $10.2 \%$ \\
\hline
\end{tabular}

Our empirical strategy measures the association between zoning and reported crime by comparing the crime rates among blocks within the same areas having different primary forms of parcel zoning. To confirm that differently zoned blocks within the same area did not differ systematically on key variables, we compared data from the 2000 Census ${ }^{164}$ for mixed- and single-zoned blocks. Specifically, we compared these blocks using the following variables: (1) percentage of African American residents, (2) percentage

160 A face block refers to the properties on opposite sides of a common street.

161 See Community Plan Area, CiTy of L.A.: DEP'T OF CiTy PlAN., http://cityplanning. lacity.org (select "General Plan"; then "Community Plans"; then "35 Community Plans") (last visited Jan. 11, 2013).

162 Higher levels of crime increase our ability to detect an effect of land use zoning on crime-assuming one exists.

163 We were, of course, unable to randomize the zoning of blocks selected in the sample. To avoid biasing the results of the analysis through block selection, we selected blocks without any knowledge of their crime rates.

164 See American FactFinder, U.S. CENSUS BUREAU, http://factfinder2.census.gov/ (last visited Jan. 11, 2012) (providing public access to data from the 2000 United States census). 
of Hispanic residents, (3) percentage of male residents under the age of twenty-five, (4) percentage of employed residents, (5) average housing tenure, ${ }^{165}$ and (6) percentage of families receiving welfare. These variables are widely used measures of social disadvantage that are correlated with neighborhood crime rates. ${ }^{166}$

Table 2 below reveals substantial variability across the eight areas of Los Angeles on the census measures. More importantly, however, Table 2 shows considerable similarity across blocks within each area-regardless of zoning classification. ${ }^{167}$ Within areas, there are no meaningful differences between mixed zoning, on the one hand, and commercial and residential zoning, on the other, relative to the percentage of African American residents, the percentage of Hispanic residents, the percentage of males under twentyfive, the percentage of employed residents, and average housing tenure. ${ }^{168}$ For the percentage of families receiving welfare, only one area showed any difference across zoning classifications: in Southeast Los Angeles, the percentage of families receiving welfare is lower in mixed-zoned blocks $(17.7 \%)$ than in other zoned blocks $(24 \%)$. Even this difference, however, is not particularly large. These findings provide some assurance that differently zoned blocks within each area have similar population attributes.

165 Average housing tenure is measured as the percentage of occupants that have resided in their current homes for five years or more.

166 See, e.g., Robert J. Sampson, Neighborhood and Crime: The Structural Determinants of Personal Victimization, 22 J. RES. CRIME \& DELINQ. 7, 13-16 (1985) (controlling for unemployment, racial composition, and residential mobility in a study of the causes of personal victimization).

167 There are only 109 unique census tracts across the 205 blocks, meaning that a number of blocks share the same census tract and, therefore, share the same census data. We do not display census data at a lower level of aggregation, such as census blocks, because the number of observations is too low to obtain reliable demographic estimates. However, when we examine census block data for the 191 unique census blocks associated with the 205 face blocks on basic racial and ethnic demographics, we see no difference across zoning classifications.

168 We do not present the statistics for percentage of Hispanics, percentage of males under twenty-five, and average housing tenure, as they were not different within any area by zone classification. 
Table 2: Comparison of Demographic Features Across Multiple versus Single Use Block Zones ${ }^{169}$

\begin{tabular}{lcccccc} 
& \multicolumn{2}{c}{ Employed (\%) } & \multicolumn{2}{c}{ African American (\%) } & \multicolumn{2}{c}{ Sample Size $(n=)$} \\
\multicolumn{1}{c}{ Area Name } & Mixed & C $\mid \mathbf{R}$ & Mixed & C $\mid \mathbf{R}$ & Mixed & C|R \\
\hline \hline Boyle Heights & 90.1 & 87.7 & .05 & .09 & 6 & 19 \\
Highland Park & 91.5 & 91.5 & .07 & 2.3 & 6 & 24 \\
Hollywood & 88.6 & 88.8 & 3.9 & 3.1 & 6 & 10 \\
San Pedro & - & 91.2 & - & 7.5 & 0 & 17 \\
South L.A. & 85.7 & 86.0 & 48.4 & 58.4 & 9 & 29 \\
Southeast L.A. & 82.9 & 82.8 & 22.3 & 29.3 & 10 & 23 \\
West Adams & 89.8 & 91.7 & 32.8 & 33.4 & 10 & 10 \\
Westlake & 86.9 & 86.4 & 3.5 & 3.1 & 7 & 14 \\
Overall Sample & 87.5 & 87.9 & 19.3 & 20.4 & 54 & 146 \\
\hline
\end{tabular}

\section{B. Data}

We constructed a data set containing data of three types: land use data on zoning, crime data at the street block-level, and observed built-environment data collected by field researchers.

\section{Land Use Data}

The land use zoning classifications for all parcels included in the study's 205 blocks were collected from publicly accessible data from the City of Los Angeles. ${ }^{170} \mathrm{We}$ employ two different classification schemes for land use.

First, we classify blocks into four broad categories: residential $(n=122$ blocks), commercial $(n=22)$, mixed-use (residential and commercial parcel zoning) $(n=57)$, and manufacturing $(n=4)$. Each block was classified based on the two most common parcel classifications on the block.

Second, we use an alternative set of categories that is more sensitive to different kinds of residential and commercial usage. This second formulation uses the following categories: multipurpose commercial zoning (containing more than a single kind of commercial zone) $(n=21)$, single-purpose commercial/industrial zoning $(n=19)$, single purpose residential zoning $(n=$

169 "Mixed" represents mixed zoning and "C|R" represents commercial or residential zoning. The three mixed zoning blocks in San Pedro had no census tract data available.

170 See ZIMAS, http://zimas.lacity.org/ (last visited Jan. 11, 2012) (providing public zoning data for the City of Los Angeles in the Zone Information and Map Access System). 
99), and mixed-purpose zoning (containing both residential and commercial zones) $(n=66)$. A simple way to conceptualize the distinction between multipurpose commercial and mixed-purpose blocks is that multipurpose commercial blocks have only commercial zoning, whereas mixed-purpose blocks have either residential zoning mixed in with commercial zoning or multiple forms of residential zoning. Given that many cities encourage mixedpurpose zoning plans, it is useful to compare multiple forms of residential zoning. One can easily imagine, for example, a zoning plan that allows mixed-purpose uses for residential and commercial zoning, but does not allow exclusionary zoning for a single residential or commercial purpose.

\section{Crime Data}

Crime data were extracted from the Los Angeles Times's open-source data on crime as reported by the Los Angeles Police Department (LAPD) and the Los Angeles Sheriff's Department (LASD). ${ }^{171}$ The number and types of reported crimes within 100 and 250 meters of each of the 205 blocks in the study were collected for a six-month interval. ${ }^{172}$ Our analyses examine total crime ${ }^{173}$ as well as assaults, burglaries, robberies, and automobile break-ins, because these offenses are most likely to occur in public view and to be influenced by characteristics of the built environment. ${ }^{174}$

171 We compared data that we obtained directly from the LAPD with the crime data posted publicly by the Los Angeles Times. We mapped the Los Angeles Times's data using ArcGIS onto police reporting districts - the smallest aggregate level of geography available for analysis captured in the LAPD database-and found 86-90\% agreement on the number and types of crimes in each district between 2009 and 2010. On average, the numbers were slightly larger in the Los Angeles Times's data because they include both LAPD and LASD crime data. The Los Angeles Times's data is geo-coded and cleaned, and includes crimes reported to the LASD, thereby making it preferable for our block-level analysis. In the subsequent empirical analysis of police reporting districts, we use only the LAPD data for the years 1994 to 2010, because the Los Angeles Times data are not available prior to 2009. About Mapping L.A., L.A. TIMES, http://projects.latimes.com/mappingla/about/\#crime-data-sources (last visited Jan. 11, 2012).

172 Specifically, we use crime data from July 1, 2010, to January 6, 2011. This time range was chosen for two reasons. First, it encompassed the period in which our field researchers conducted the systematic field observations discussed infra in subsection III.C.3. Second, it is long enough to guard against drawing conclusions from random week-by-week fluctuations.

173 We use Part 1 index felony offenses reported by the LAPD and LASD, which include assault, burglary, homicide, theft, theft from vehicle, grand-theft automobile, rape, and robbery.

174 It is worth noting that we only observe reported crime. Ideally we would want information about unreported crime as well. It is theoretically possible that zoning or land use might affect the likelihood that a crime is reported, but we are not aware of any research suggesting that these offenses are underreported by land use. 


\section{Built Environment Data}

Data on the built environment of blocks in the study were collected using systematic social observation. We modified and applied data collection instruments that were developed in a previous study of Los Angeles neighborhoods. ${ }^{175}$ Field observers examined blocks in the study over a twelve-week period, from August 19, 2010, to November 13, 2010. ${ }^{176}$

Following the prior scholarly work on the relationship between the built environment and crime, ${ }^{177}$ our systematic observation collected data to construct six measures of the built environment. First, we measured the general condition of a block, which included observers' overall assessment of the condition of street surfaces for driving, the condition of the sidewalks for walking, and the condition of residential, commercial, and industrial buildings. Second, we measured physical disorder through the presence of garbage, litter, and broken glass; signs of illegal drug activity; cigarette butts; feces or urine; and graffiti. Third, we measured territoriality by recording the presence of well-tended yards, flowerboxes or planters, and flags on properties. Fourth, following Jacobs's work on the potential for "eyes on the street"178 to reduce crime, we measured natural surveillance: observers estimated the number of buildings standing more than fifteen feet from the street and recorded the presence of front porches, driveways, and buildings without windows. ${ }^{179}$ Fifth, we captured data on the presence of establishments that attract crime. We included a sum of binary variables measuring the presence of bars, pawnshops, check cashing businesses, liquor

175 See JOHN MACDONALd ET AL., NeIGHBORHoOd EFFECTS ON CRIME AND Youth VIOLENCE: THE ROLE OF BusinesS IMPROVEMENT DisTRICTS IN LOS ANGELES 35-37 (2009) (describing the study's data collection protocol).

176 Observational data on the built environment were collected by field observers after they completed a three-step training course. In the first step, observers reviewed the coding items with one of the investigators (Dr. Ricky Bluthenthal) and an experienced coding staff member (Heather Guenzel). Observers were provided a description and rationale for each item, along with examples of each response category. In the second step, experienced staff held practice sessions with the trainees. In the field, staff addressed incongruent responses and discussed interpretations of ambiguous features of the physical and social environment. In the third step, observers independently coded the same face blocks. Initial congruence on responses was very high for most items. There was $95 \%$ agreement within one interval on most items (i.e., responses that were "good" or "very good" were considered concurrent). On items of disagreement, retraining was conducted, and in some cases, response categories were clarified or amended in consultation with the principal investigators to improve consistency in data collection.

177 See supra Section II.A.

178 See JACOBS, supra note 12 , at 35 .

179 We include this measure because some theorists have suggested that natural surveillance reduces crime. See, e.g., id. 
stores, and convenience stores on each block. ${ }^{180}$ Sixth, we measured the walkability of each block. Walkability may affect crime, either by increasing street traffic and "eyes on the street" or by increasing the number of potential victims of crime. We therefore obtained "Walk Score" data, based on the proximity of nearby amenities that decrease the need for personal automobiles, such as grocery stores, coffee shops, and public transit. ${ }^{181}$

We computed each measure of the built environment by summing its individual items. Higher scores indicate greater levels of an attribute. Correlations among our different measures of the built environment were small, ${ }^{182}$ suggesting that they are, in fact, independent dimensions of the built environment.

\section{Results}

\section{The Association Between Zoning Classifications and Crime}

We present a series of regressions to estimate the effect of a block's land use classification on crime within 100 and 250 meters. ${ }^{183}$ Table 3 below presents the results of a model based upon the first classification of zoning described above, namely, one that divides blocks into residential, commercial, and mixed-use categories. ${ }^{184}$ The entries in the table represent incidence-

180 See Casteel \& Peek-Asa, supra note 68; Scribner et al., supra note 137; Sherman et al., supra note 146 at 45 tbl.5; Thomas J. Miles, Markets for Stolen Property: Pawnshops and Crime 25 (Jan. 24, 2008) (unpublished manuscript), available at http://www.law.umich.edu/centersand programs/lawandeconomics/workshops/Documents/Winter2008/miles.pdf (finding that "pawnshops increase crimes in which pawnable goods are taken and that they have minimal effect on other types of criminal activity").

181 We obtained this data through WalkScore.com. Its index of walkability has been used in a wide variety of research. See Walkability Research, WALK SCORE PROF., http://www.walkscore.com/ professional/walkability-research.php (last visited Jan. 11, 2012) (listing studies that have used Walk Score data).

182 The largest bivariate correlation was between surveillance and crime attractors $(r=-0.36)$.

183 We use these limited distances because larger distances lead to overlapping blocks. We also estimated regression models at 500 meters as a falsification test because we would not expect land use on a specific block to influence crime 500 meters away. The results from these models show no relationship between crime and zoning variation.

184 Model 1 is defined as: Crime $_{i a}=\mu+\beta$ Residential $_{i}+\Psi$ Commercial $_{i}+\delta$ Area $_{a}+s_{i a}$. In this model, Residential is a dummy variable indicating whether observed block $i$ has residential zoning, and Commercial is a dummy variable indicating whether observed block $i$ has commercial zoning. Mixed-use is the reference category and is not included in the regression equation. Area is a categorical variable indicating the Community Plan Area in which the observed block is located. $\delta$ represents a fixed-effect parameter for each Community Plan Area to control for overall differences in crime in these areas. Crimes are recorded as counts for each block, and we use Poisson regression models $\left(Y_{i a} \sim\right.$ Poisson $\left.\left(\lambda_{i a}\right)\right)$ to estimate the logarithm of the count. See A. COLIN CAMERon \& Pravin K. TRIVEDI, Regression Analysis of Count Data 1, 8-10 (1998) (describing the mathematical theory underlying Poisson regression and its application to count data). 
rate ratios. An incidence-rate ratio of 2.0 , for example, means that twice the expected number of crimes occurred on the block. Mixed-use blocks serve as the reference category. In other words, the incidence-rate ratios for residential and commercial blocks are measured relative to the average crime rate on mixed-use blocks. Table 3 below reveals that residential blocks have significantly less crime in nearly all categories than mixed-use blocks, in both the 100- and 250-meter models. The sole exception to this general pattern is burglary, which is lower in mixed-use areas than in strictly commercial or strictly residential areas. ${ }^{185} \mathrm{We}$ also observe smaller coefficients at the 250 meter metric, which is expected as crimes from blocks that are further away are included in the count. Interestingly, these results provide empirical support for the early defenders of zoning who argued in favor of residentialonly zoning on the grounds that commercial establishments tend to increase crime. ${ }^{186}$ Apparently, their intuition was correct.

185 We estimate these models using robust standard errors to adjust for overdispersion around the expected average count of crimes on blocks. Though robust standard errors do not influence the size of our estimates, the $p$-values in some of the models in Table 3 (including auto theft at 100 meters, total crime at 250 meters, and theft at 250 meters) exceed 0.05 (two-tailed test) for commercial zoning, meaning those findings are not statistically significant. The relatively small sample size for commercially zoned blocks leads to more variability around the average, which is adjusted by using a wider standard error according to the robust standard errors specifications.

186 See, e.g., Miller v. Bd. of Pub. Works, 234 P. 381, 386-87 (Cal. 1925) (discussing residential zoning as a means of promoting public health and morals); State ex rel. Civello v. New Orleans, 97 So. 440, 443-44 (La. 1923) (finding city zoning ordinances justified by concerns over public safety and general welfare); State ex rel. Morris v. City of E. Cleveland, 22 Ohio N.P. (n.s.) 549, 556 (C.P. Cuyahoga County 1920) (finding a zoning ordinance limiting the construction of apartment buildings to be within the city's police power because it safeguards public health and morals). From a policy perspective, however, this finding is of limited utility because it is difficult to conceive of constructing a large city with only residential zoning. 
Table 3: Estimated Effect of Zoning Classifications on Crime ${ }^{187}$

\begin{tabular}{|c|c|c|c|c|c|c|}
\hline 100 meters & Total & Assault & Robbery & Theft & Burglary & $\begin{array}{l}\text { Auto } \\
\text { Theft }\end{array}$ \\
\hline \multirow[t]{2}{*}{ Residential } & $0.5^{*}$ & 0.78 & $0.41^{*}$ & $0.34^{*}$ & $\begin{array}{l}1.81^{*} \\
\end{array}$ & 0.84 \\
\hline & $\left(.5^{0-} .68\right)$ & $\left(.53^{-1.13}\right)$ & $(.29-.59)$ & $\left(.23^{-} .50\right)$ & $(1.09-3.00)$ & $\left(.5^{8-1.22)}\right.$ \\
\hline \multirow[t]{2}{*}{ Commercial188 } & $2.43^{*}$ & $1.93^{*}$ & $2.13^{*}$ & $4.86^{*}$ & $3 \cdot 33^{*}$ & $1.71^{*}$ \\
\hline & $(2.09-2.83)$ & $(1.26-2.94)$ & $(1.52-2.96)$ & $(3.55-6.64)$ & $(1.90-5.82)$ & $(1.12-2.63)$ \\
\hline Pseudo $\mathrm{R}^{2}$ & 0.40 & 0.26 & 0.35 & 0.39 & 0.26 & 0.28 \\
\hline 250 meters & Total & Assault & Robbery & Theft & Burglary & $\begin{array}{l}\text { Auto } \\
\text { Theft }\end{array}$ \\
\hline \multirow[t]{2}{*}{ Residential } & $0.67^{*}$ & 0.94 & $0.65^{*}$ & $0.42^{*}$ & $\begin{array}{l}1.07 \\
\end{array}$ & $0.68^{*}$ \\
\hline & $\left(.63^{-} \cdot 71\right)$ & $(.78-1.14)$ & $\left(.55^{-}-.77\right)$ & $(.36-.49)$ & $(.90-1.28)$ & $\left(.5^{8-.79)}\right.$ \\
\hline \multirow[t]{2}{*}{ Commercial } & $1.36^{*}$ & $1.68^{*}$ & $1.66^{*}$ & $1.54^{*}$ & 1.20 & 0.95 \\
\hline & $(1.26-1.47)$ & $\left(1.35^{-2.10}\right)$ & $(1.38-1.99)$ & $(1.32-1.79)$ & $\left(.95^{-1.51)}\right.$ & $\left(.77^{-1.17}\right)$ \\
\hline Pseudo $\mathrm{R}^{2}$ & 0.46 & 0.30 & 0.37 & 0.30 & 0.41 & 0.39 \\
\hline
\end{tabular}

${ }^{*} p<0.05$ (two-tailed); $n=205$ blocks. All models include area-level fixed effects.

In our next model, we use the second categorization of blocks described above. We divide blocks into residential, multiple-use commercial, singleuse commercial, and mixed use (which includes residential-use, commercialuse and residential-use mixed together). Mixed-use serves as the reference group. Table 4 below presents results from the model using this alternative categorization of the blocks. ${ }^{189}$ Zoning classification predicts considerable variation in crime across blocks. For example, multiple-use commercial blocks have an expected total crime count that is roughly twice that of blocks mixing in residential uses. Single-use commercially zoned blocks have expected crime counts that are approximately forty-five percent higher than blocks with residential uses mixed in. Contrary to some predictions from urban planning theory, which suggest that mixed-land use zoning will

187 Both regression models include fixed effects for Community Plan Areas. The count multiplier or incidence rate ratios are displayed, along with ninety-five percent confidence intervals in parentheses. We also estimated the models in Table 3 using robust standard errors to adjust for over dispersion. See supra note 185. "Total" crime represents the sum of homicide, rape, assault, robbery, theft, theft from automobile, burglary, and auto theft.

188 Because only four blocks are zoned for manufacturing, they are included with commerciallyzoned blocks for a total of twenty-six blocks in the analysis.

189 Model 2 is defined as: Crime $_{i a}=\mu+$ BResidential $_{i}+$ YCommercial-Single $_{i}+\lambda$ Commercial $_{-}$ Multiple $_{i}+\delta$ Areas $_{a}+s_{i a}$. 
reduce crime, blocks with a single type of residential zoning have the lowest level of crime.

Table 4: Estimated Effect of Refined Zoning Classifications on Crime ${ }^{190}$

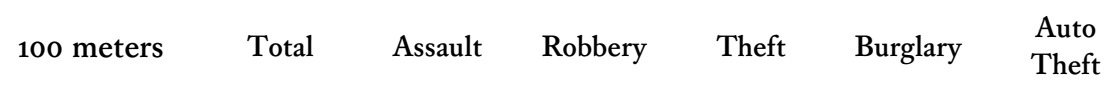

\begin{tabular}{|c|c|c|c|c|c|c|}
\hline $\begin{array}{l}\text { Single } \\
\text { Residential }\end{array}$ & $\begin{array}{l}0.52^{*} \\
\left(.44^{-.61)}\right.\end{array}$ & $\begin{array}{c}0.70^{*} \\
(.47-1.05)\end{array}$ & $\begin{array}{c}0.31^{*} \\
(.20-.46)\end{array}$ & $\begin{array}{l}0.46^{*} \\
(.31-.70)\end{array}$ & $\begin{array}{c}0.56^{*} \\
\left(.37^{-.85)}\right.\end{array}$ & $\begin{array}{c}0.74 \\
(.51-1.08)\end{array}$ \\
\hline $\begin{array}{l}\text { Multi- } \\
\text { Commercial }\end{array}$ & $\begin{array}{c}2.48^{*} \\
(2.12-2.90)\end{array}$ & $\begin{array}{c}1.71^{*} \\
(1.07-2.72)\end{array}$ & $\begin{array}{c}1.92^{*} \\
(1.36-2.72)\end{array}$ & $\begin{array}{c}6.10^{*} \\
(4.25-8.54)\end{array}$ & $\begin{array}{c}1.21 \\
(.72-2.05)\end{array}$ & $\begin{array}{c}1.79^{*} \\
\left(1.14^{-2.80}\right)\end{array}$ \\
\hline $\begin{array}{l}\text { Single- } \\
\text { Commercial }\end{array}$ & $\begin{array}{c}1.45^{*} \\
(1.20-1.75)\end{array}$ & $\begin{array}{c}1.50^{*} \\
(.92-2.45)\end{array}$ & $\begin{array}{c}1.08 \\
(.70-1.68)\end{array}$ & $\begin{array}{c}3.18^{*} \\
(2.12-4.76)\end{array}$ & $\begin{array}{c}1.27 \\
(.76-2.13)\end{array}$ & $\begin{array}{c}1.22 \\
\left(.74^{-2.01)}\right.\end{array}$ \\
\hline Pseudo $\mathrm{R}^{2}$ & 0.39 & 0.25 & 0.34 & 0.34 & 0.25 & 0.28 \\
\hline 250 meters & Total & Assault & Robbery & Theft & Burglary & $\begin{array}{l}\text { Auto } \\
\text { Theft }\end{array}$ \\
\hline $\begin{array}{l}\text { Single } \\
\text { Residential }\end{array}$ & $\begin{array}{c}0.95 \\
(.88-1.02)\end{array}$ & $\begin{array}{c}0.95 \\
(.79-1.14)\end{array}$ & $\begin{array}{c}0.82^{*} \\
(.69-.98)\end{array}$ & $\begin{array}{c}1.05 \\
(.88-1.24)\end{array}$ & $\begin{array}{c}0.92 \\
\left(.77^{-1.10)}\right.\end{array}$ & $\begin{array}{c}1.01 \\
(.83-1.20)\end{array}$ \\
\hline $\begin{array}{l}\text { Multi- } \\
\text { Commercial }\end{array}$ & $\begin{array}{c}1.97^{*} \\
(1.81-2.14)\end{array}$ & $\begin{array}{c}1.58^{*} \\
(1.22-1.94)\end{array}$ & $\begin{array}{c}1.80^{*} \\
(1.48-2.20)\end{array}$ & $\begin{array}{c}4.25^{*} \\
\left(3.55^{-5} .07\right)\end{array}$ & $\begin{array}{c}1.13 \\
(.88-1.43)\end{array}$ & $\begin{array}{c}1.42^{*} \\
\left(1.13^{-1.78)}\right.\end{array}$ \\
\hline $\begin{array}{l}\text { Single- } \\
\text { Commercial }\end{array}$ & $\begin{array}{c}1.47^{*} \\
\left(1.34^{-1.61)}\right.\end{array}$ & $\begin{array}{c}1.18 \\
(.91-1.14)\end{array}$ & $\begin{array}{c}1.32^{*} \\
(1.04-1.66)\end{array}$ & $\begin{array}{c}2.65^{*} \\
(2.16-3.24)\end{array}$ & $\begin{array}{c}1.10 \\
(.86-1.42)\end{array}$ & $\begin{array}{c}1.20 \\
\left(.95^{-1.52}\right)\end{array}$ \\
\hline Pseudo $\mathrm{R}^{2}$ & 0.46 & 0.29 & 0.35 & 0.33 & 0.41 & 0.38 \\
\hline
\end{tabular}

${ }^{*} p<0.05$ (two-tailed); $n=205$ blocks. All models include area-level fixed effects.

190 "Total" represents the sum of homicide, rape, assault, robbery, theft, theft from automobile, burglary, and auto theft. The count-multiplier or incidence-rate ratios are displayed, along with $95 \%$ confidence intervals in parentheses. We also estimated the models in Table 4 using robust standard errors to adjust for overdispersion. See supra note 185. 
These results are generally consistent with the situational crime prevention literature, which predicts that areas with commercial establishments create more attractive crime opportunities. ${ }^{191}$ According to this theory, establishments that attract strangers who are potential offenders or suitable criminal targets will increase criminal victimization. Consistent with this theory, our results show that, on average, residential-only areas with likely fewer strangers have less crime, whereas commercially zoned areas with likely more strangers have higher rates of crime.

Figure 1 below shows the expected total crime counts at 100 meters for the different types of zoning. The expected crime counts are substantially lower in multiple zoned areas than in single commercially zoned blocks.

Figure 1: Estimated Effect of Zoning on Crime Counts at 100 Meters

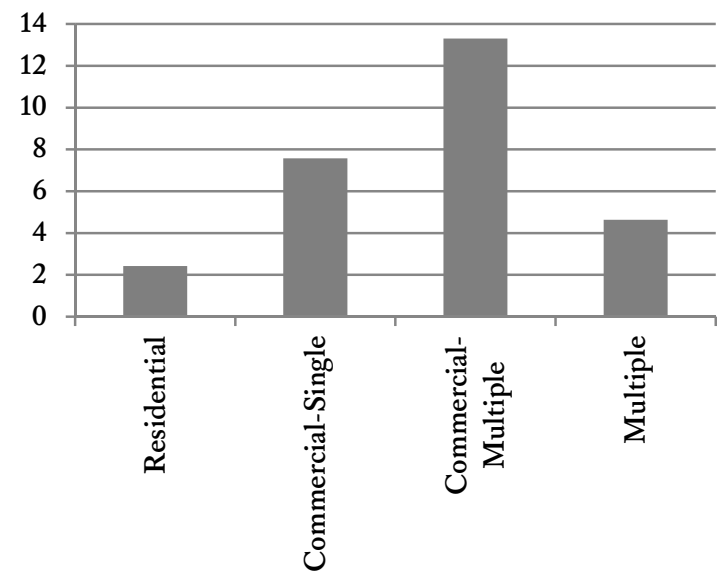

2. The Association Between Zoning Homogeneity and Crime

Zoning homogeneity refers to the degree to which parcels on a block share the same zoning classifications. The concept of zoning homogeneity thus complements the Jacobs argument that mixed-use zoning increases the "eyes on the street," 192 and to the situational crime prevention literature, which argues that multiple-form zoning encourages establishments such as

191 See, e.g., Sherman et al., supra note 146 , at 45 tbl. 5 (reporting that 36 of the top 42 areas of predatory crimes in a study of Minneapolis were nonresidential areas).

192 See JACOBS, supra note 12 and accompanying text. 
bars and restaurants which often produce crime. ${ }^{193}$ Here, we estimate the effect of zoning homogeneity of crime within 100 and 250 meters of the street blocks in the study.

We measure zoning homogeneity with the Herfindahl index of the two most common types of zoning on each block. ${ }^{194}$ A lower Herfindahl index indicates less homogeneity in zoning types on the block. A block with only one kind of zoning has an index score of one while a block with many different kinds of zoning has an index score between zero and one, with a lower score indicating more types of zoning on the block.

Table 5 below presents our estimates of the effect of zoning homogeneity on crime. ${ }^{195}$ Zoning homogeneity is consistently associated with lower crime at both 100 and 250 meter distances. Increasing the homogeneity of zoning is associated with a $73 \%$ reduction in the predicted count of all crimes at the 100-meter range. ${ }^{196}$ The effect of zoning homogeneity diminishes as the range expands to 250 meters.

193 See supra notes 131-137 and accompanying text.

194 We calculate the Herfindahl index as the sum of squares of the proportion of parcels for the two most common land use classifications on each block. See Stephen A. Rhoades, The Herfindahl-Hirschman Index, 79 FED. RES. BULL. 188, 188-89 (1993) (defining the index). The mean of the Herfindahl index for the 205 blocks in the study is 0.77 , and the standard deviation is 0.23. The Herfindahl index for the blocks in the study range from 0.22 to 1.o.

195 Model 3 is as follows: Crime $i a=\mu+\beta \Sigma p_{\mathrm{i}}{ }^{2}+\delta$ Areas $_{a}+s_{i a}$, where $\Sigma p_{\mathrm{i}}{ }^{2}$ represents the Herfindahl index for each block $i$.

196 We also estimated models in Table 5 using robust standard errors to adjust for overdispersion. See supra note 185 . This has no influence on the size of our estimates, but expands the standard errors making most of the results no longer significant at the $p<0.05$ level. 
Table 5: Estimated Effect of Zoning Homogeneity on Crime ${ }^{197}$

\begin{tabular}{|c|c|c|c|c|c|c|}
\hline 100 meters & Total & Assault & Robbery & Theft & Burglary & $\begin{array}{l}\text { Auto } \\
\text { Theft }\end{array}$ \\
\hline Homogeneity & $\begin{array}{l}0.26^{*} \\
(.21-.34)\end{array}$ & $\begin{array}{c}0.49^{*} \\
(.26-.93)\end{array}$ & $\begin{array}{c}0.38^{*} \\
(.22-.67)\end{array}$ & $\begin{array}{c}0.06^{*} \\
\left(.03^{-.11)}\right.\end{array}$ & $\begin{array}{c}0.50^{*} \\
\left(.25^{-1.01)}\right.\end{array}$ & $\begin{array}{c}0.55^{* *} \\
(.29-1.02)\end{array}$ \\
\hline Pseudo $\mathrm{R}^{2}$ & 0.32 & 0.23 & 0.26 & 0.25 & 0.24 & 0.26 \\
\hline 250 meters & Total & Assault & Robbery & Theft & Burglary & $\begin{array}{l}\text { Auto } \\
\text { Theft }\end{array}$ \\
\hline Homogeneity & $\begin{array}{c}0.81^{*} \\
(.72-.92)\end{array}$ & $\begin{array}{c}0.92 \\
(.67-1.27)\end{array}$ & $\begin{array}{c}1.00 \\
(.75-1.35)\end{array}$ & $\begin{array}{c}0.50^{*} \\
(.39-.64)\end{array}$ & $\begin{array}{l}1.31^{* *} \\
(.95-1.81)\end{array}$ & $\begin{array}{c}1.14 \\
(.85-1.54)\end{array}$ \\
\hline Pseudo $\mathrm{R}^{2}$ & 0.46 & 0.29 & 0.32 & 0.21 & 0.41 & 0.37 \\
\hline
\end{tabular}

It is possible these results are simply driven by the lower crime rates on purely residential blocks which make up nearly half $(n=99)$ of the blocks in the study. In order to test that hypothesis, we repeat the analysis and include interaction terms between the Herfindahl index, and each of the zoning classifications. ${ }^{198} \mathrm{We}$ find nearly identical effects: zoning homogeneity is associated with lower predicted crime counts in residential, commercial, and mixed zoned areas. The effects are largest in residential areas. This suggests that the results in Table 5 are not merely driven by lower crime in uniformly residential areas. Rather, even among blocks with the same zoning classification, homogeneity is associated with lower crime. Figure 2 below displays this relationship by graphing the expected crime rate for residential zones, and other zones by zoning homogeneity.

197 Zoning homogeneity is measured by the Herfindahl index from the sum of squares of the proportion of parcels for the two primary classifications on each block. See supra note 194. All regressions include area fixed effects. The count multiplier or incidence rate ratios are displayed along with $95 \%$ confidence intervals in parentheses. "Total" represents the sum of homicide, rape, assault, robbery, theft, theft from automobile, burglary, and auto theft.

198 The results of this regression are available from the authors upon request. 
Figure 2: Predicted Crimes by Zoning Homogeneity ${ }^{199}$

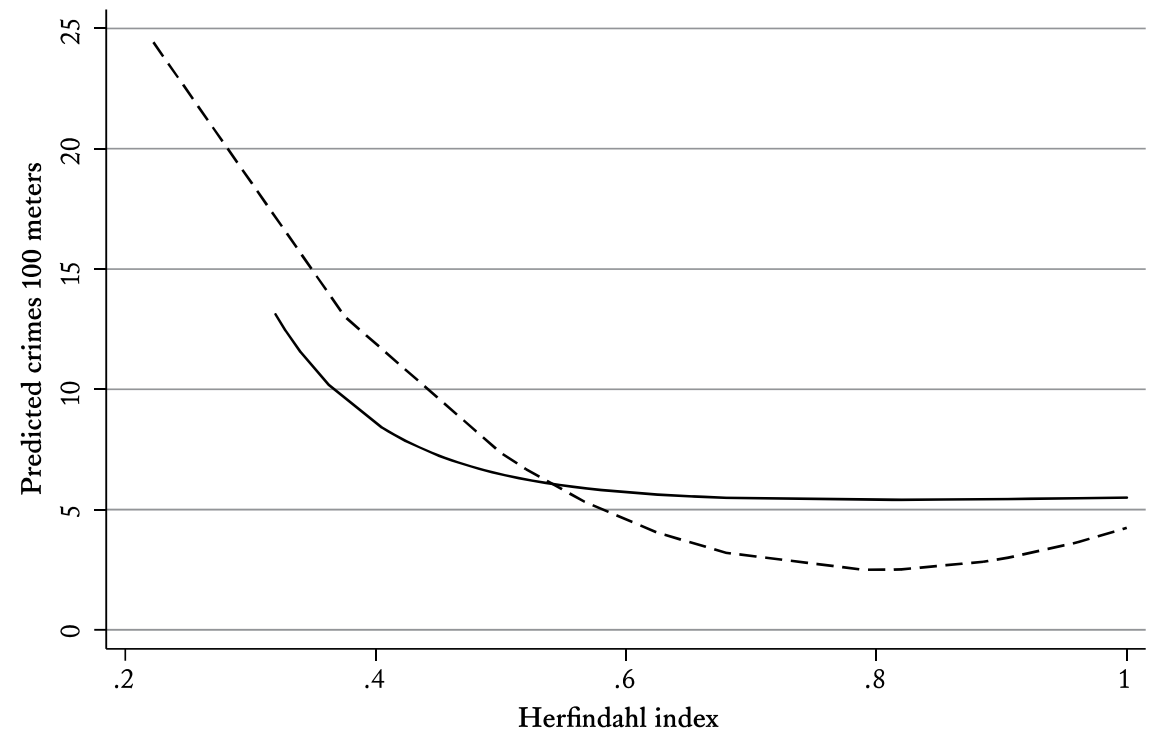

Other Zones $\quad$ - - - - Single Residential Zones

Land use homogeneity may reduce crime in residential areas by reducing street traffic, or in commercial areas by producing dominant business patterns that reduce opportunities for crime. This theory is generally consistent with the situational crime prevention literature. ${ }^{200}$

Our empirical results suggest that zoning has a substantial effect on crime. However, these results do not suggest a precise mechanism. ${ }^{201} \mathrm{We}$ turn to that question next.

199 Zoning homogeneity is measured by the Herfindahl index. See supra note 194. This figure plots predicted crime with a fractional polynomial smoother to display nonlinearity.

200 See supra notes 131-137 and accompanying text.

201 Since we observe only certain blocks within a neighborhood, it is possible that the reduction in crime we observe is accompanied by a rise in crime elsewhere. In other words, it is possible that zoning adjustments displace crime, rather than reduce it citywide. However, studies of local crime prevention strategies suggest that displacement seldom occurs. A review of 102 situational crime prevention evaluations reported that crime displacement is about as likely as its opposite, the diffusion of crime prevention benefits. Rob T. Guerette \& Kate J. Bowers, Assessing the Extent of Crime Displacement and Diffusion of Benefits: A Review of Situational Crime Prevention Evaluations, 47 CRIMINOLOGY 1331, 1356-57 (2009). The review also found that, when displacement was observed, it was smaller than the direct effect of the intervention itself. Id. 


\section{The Association between Zoning and the Built Environment}

Many scholars have hypothesized that the built environment plays an important role in affecting crime. ${ }^{202}$ In order to understand how the built environment mediates the relationship between zoning and crime, we model our measures of the built environment on zoning classifications. ${ }^{203}$ Mixed-use serves as the reference category. Table 6 below provides the results from six different models, one for each of the built-environment measures. The table indicates the average score for the built environment measures across zoning classifications. For example, blocks that are zoned for one residential purpose exhibit a $15 \%$ lower score of general condition than mixed-purpose blocks. ${ }^{204}$ Since the different built environment measures are scaled differently, one cannot directly compare the scores between different built environment measures (between columns).

The R-squared reports the percentage of variation in each of the builtenvironment measures explained by zoning classification and area-level fixed effects. Zoning explains a larger share of the variation in general condition, surveillance, crime attractors, and walk score, than it does in disorder and territoriality.

Zoning for multiple commercial uses is more strongly correlated with natural surveillance than is zoning for a single commercial zoned block. Multiple- and single-commercial use zoning are correlated with more crime attractors, such as liquor stores and bars, whereas residential-only zoning is correlated with fewer crime attractors. Commercially zoned blocks have higher values of walkability. These findings suggest some potential mechanisms through which zoning influences features of the built environment that correlate with crime.

202 See supra Section II.A.

203 Model 4 is defined as follows: Built Environment $t_{i a}=\mu+$ BResidential $_{i}+$ YCommercial- $^{-}$ Single $_{i}+\lambda$ Commercial-Multiple $_{i}+\delta$ Areas $_{a}+s_{i a}$.

204 This can be calculated by dividing the coefficient $(-1.42)$ by the sample mean (9.33). 
Table 6: Estimated Effect of Zoning Classifications on

Built Environment Measures ${ }^{205}$

\begin{tabular}{lcccccc} 
& $\begin{array}{c}\text { General } \\
\text { Condition }\end{array}$ & Disorder & Territoriality & Surveillance & $\begin{array}{c}\text { Crime } \\
\text { Attractors }\end{array}$ & Walk Score \\
\hline \hline \multirow{2}{*}{ Single Residential } & $-1.42^{*}$ & -.28 & .04 & .34 & $-.31^{*}$ & -2.07 \\
& $(.345)$ & $(.32)$ & $(.12)$ & $(.343)$ & $(.12)$ & $(2.03)$ \\
\multirow{4}{*}{ Multi-Commercial } & 0.85 & 0.79 & .19 & $-1.96^{*}$ & $.43^{*}$ & $11.07^{*}$ \\
& $(.547)$ & $(.51)$ & $(.195)$ & $(.54)$ & $(.19)$ & $(3.22)$ \\
\multirow{2}{*}{ Single-Commercial } & 0.66 & 0.39 & -.03 & $-3.45^{*}$ & $1.36^{*}$ & $10.06^{*}$ \\
& $(.553)$ & $(.51)$ & $(.197)$ & $(.54)$ & $(.192)$ & $(3.25)$ \\
\hline $\mathrm{R}^{2}$ & 0.30 & 0.17 & 0.08 & 0.34 & 0.34 & 0.37 \\
\multirow{2}{*}{ Sample Mean (SD) } & 9.33 & 8.62 & 8.43 & 13.39 & .40 & 67.69 \\
& $(2.42)$ & $(2.08)$ & $(.75)$ & $(2.48)$ & $(.87)$ & $(15.14)$ \\
\hline
\end{tabular}

${ }^{*} p<0.05$ (two-tailed); $n=205$ blocks. All models include area-level fixed effects.

We turn now to the effect of zoning homogeneity on the built environment. Table 7 below presents our estimates of the effect of zoning homogeneity on our measures of the built environment. ${ }^{206}$ The R-squared figures indicate that, with the exception of walk score, zoning homogeneity explains very little variation in the built environment measures, suggesting that zoning homogeneity is only weakly related to our built environment scores. Zoning homogeneity is associated with inferior general block conditions (e.g., quality of streets, sidewalks, and buildings), higher natural surveillance, and lower walkability. The negative association between homogeneity and walkability is best explained by the greater distance from homogeneously zoned blocks to business establishments, schools, and parks, which provide walking destinations. Overall, these results for zoning homogeneity are consistent with the results from our analysis of the effect of zoning classification on the built environment (in Table 6). ${ }^{207}$

205 Standard errors are noted in parentheses. We also estimated models in Table 6 using robust standard errors to adjust for overdispersion. See supra note 185. This has no influence on the size of our estimates, but the standard errors expand making the results for multiple commercial zoning no longer significantly related to crime attractors at the $p<0.05$ level.

206 Model 5 is defined as follows: Built Environment $i_{i a}=\mu+\beta \Sigma \mathrm{p}_{i}{ }^{2}+\delta$ Areas $_{a}+s_{i a}$.

207 The percentage of variation is lower in these models, however. We also estimated the models in Table 7 using robust standard errors to adjust for over dispersion. See supra note 194. In this analysis, the standard errors expanded, but the significance levels did not change substantively. 
Table 7: Estimated Effect of Zoning Homogeneity on Built Environment ${ }^{208}$

\begin{tabular}{lcccccc} 
& $\begin{array}{c}\text { General } \\
\text { Condition }\end{array}$ & Disorder & Territorial & Surveillance & $\begin{array}{c}\text { Crime } \\
\text { Attractors }\end{array}$ & Walk Score \\
\hline \hline Homogeneity ${ }^{209}$ & $-1.76^{*}$ & -.605 & -.004 & $1.37^{* *}$ & -.10 & $-8.71^{*}$ \\
& $(.682)$ & $(.606)$ & $(.229)$ & $(.727)$ & $(.268)$ & $(3.98)$ \\
$\mathrm{R}^{2}$ & 0.20 & 0.15 & 0.08 & 0.14 & 0.05 & 0.30 \\
Sample Mean & 9.33 & 8.62 & 8.43 & 13.39 & .40 & 67.69 \\
$(\mathrm{SD})$ & $(2.42)$ & $(2.08)$ & $(.75)$ & $(2.48)$ & $(.87)$ & $(15.14)$ \\
\hline${ }^{*} p<0.05 ;{ }^{* *} p<0.10$ (two-tailed); $n=205$ blocks. All models include area-level fixed \\
effects.
\end{tabular}

\section{The Built Environment as a Mediator for the Association} Between Land Use and Crime

We next consider questions with important policy implications: How much variation in crime is predicted by land use zoning if we assume that zoning affects crime only through its effects on the built environment? Why is this important for policy? If a sufficient share of crime is predicted by the effects of zoning on the built environment, we could imagine zoning these blocks to be more mixed by adding residential parcels to the blocks.

To measure the effect of zoning on crime through the built environment, we use the predicted built environment scores from Table 6. We then compute the correlation between crime and the predicted built environment values from zoning classifications. ${ }^{210}$ The results indicate the theoretical average crime rate on the blocks in our study were expected built environment scores based on zoning classifications.

By using the built environment scores that are predicted by zoning rather than the actual built environment scores, we diminish the risk of endogeneitythe possibility that the relationship observed is the result of crime affecting the built environment rather than the built environment affecting crime. Because the built environment score we use is predicted by zoning and zoning is much less likely to be affected by crime than the built environment, we

208 Standard errors are noted in parentheses.

209 Zoning homogeneity is measured by the Herfindahl index. See supra note $18_{5}$.

210 We specifically rely on each block's predicted built environment measure (estimated from zoning classifications and controlling for the area of Los Angeles) to predict the crime rate. This assures that the correlation between the built environment measure and crime is at least a partial function of the zoning classifications, thereby reducing the influence of endogeneity. 
minimize this risk. ${ }^{211}$ A strong association between the predicted built environment score and crime would provide plausible evidence that zoning affects crime through its effect on the built environment.

Table 8 below shows the estimated effects of the built environment on crime, as predicted by zoning classifications. ${ }^{212}$ The built-environment measures, as predicted by zoning classification, are correlated with crime. ${ }^{213}$ If one controls for zoning, for example, blocks with higher walk scores have slightly lower expected crime counts in the adjacent area. Areas predicted by zoning classification to have higher disorder are associated with higher crime counts of all forms - with increases ranging from 1.5 to 2.8 times the base level. Blocks that are predicted to have a higher presence of crime attractors are associated with higher crime as well.

Contrary to expectations, however, the predicted general condition and territoriality of blocks are associated with higher expected crime rates. One explanation for this counterintuitive finding is that the results from our model predicting built environment measures in Table 6 showed that zoning itself explained relatively little variation in general condition and territoriality. This suggests that the physical conditions of roadways, sidewalks, and buildings are not largely determined by zoning differences within the same areas of Los Angeles. In other words, the general condition of blocks does not vary greatly within areas across zoning classifications.

211 Our measures of the built environment are likely to be more sensitive to crime than zoning. The general condition of the block, for example, will be affected if crime drives out residents and businesses that maintain the block. Similarly, our measures of physical disorder are likely to be affected by a similar dynamic. See TAYLOR, supra note 125 , at 171 (finding that crime causes subsequent disorder). Because a change in formal zoning requires a legal process, which takes time, effort, and money, it is less likely to be directly affected by crime.

212 Table 8 is a model of the partial correlation of the endogenous built-environment variables on crime, developed by their predicted levels from the zoning classifications. There are separate models for each row in Table 8 , as each model has the same set of predictors. These are simply descriptive models, as the directions of the pathways were imposed and the correlations in errors between models were assumed to be independent, which are strong assumptions for this set of structural equation models. We also estimated these models with robust standard errors. See supra note 185 . In this analysis, the coefficients for predicted territorial levels were no longer significant at the $p<0.05$ level for total crime, robbery, theft, or auto theft. The coefficient for the predicted value of surveillance was no longer significantly correlated at the $p<0.05$ level with total crime. The coefficients for predicted level of crime attractors were no longer significant at the $p<0.05$ level for assault, burglary, and auto theft. The coefficients on the predicted walk scores were also no longer statistically significant at the $p<0.05$ level for total crime and robbery.

213 The results are substantively similar when estimated at the 250-meter range. 
Table 8: Effects of Built Environment on Crime as Predicted by Zoning Classifications at 100 meters ${ }^{214}$

\begin{tabular}{lcccccc} 
& Total & Assault & Robbery & Theft & Burglary & $\begin{array}{c}\text { Auto } \\
\text { Theft }\end{array}$ \\
\hline \hline General & $1.5^{*}$ & $1.5^{*}$ & $1.85^{*}$ & $1.61^{*}$ & $1.49^{*}$ & $1.44^{*}$ \\
Condition & $(.037)$ & $(.094)$ & $(.107)$ & $(.082)$ & $(.10)$ & $(.085)$ \\
& $2.07^{*}$ & $2.09^{*}$ & $2.13^{*}$ & $2.89^{*}$ & $1.71^{*}$ & $1.78^{*}$ \\
Disorder & $(.068)$ & $(.185)$ & $(.166)$ & $(.213)$ & $(.162)$ & $(.151)$ \\
& $3.21^{*}$ & $2.67^{*}$ & $4.04^{*}$ & $5.34^{*}$ & 1.47 & $2.63^{*}$ \\
Territorial & $(.437)$ & $(.965)$ & $(1.30)$ & $(1.57)$ & $\left(.57^{*}\right)$ & $(.920)$ \\
& $0.90^{*}$ & 0.98 & 0.92 & $0.79^{*}$ & 0.94 & 0.97 \\
Surveillance & $(.017)$ & $(.054)$ & $(.042)$ & $(.02)$ & $(.054)$ & $(.050)$ \\
& $1.66^{*}$ & $1.41^{*}$ & $1.72^{*}$ & $2.17^{*}$ & $1.52^{*}$ & $1.35^{*}$ \\
Attractors & $(.080)$ & $(.193)$ & $(.194)$ & $(.208)$ & $(.218)$ & $(.181)$ \\
& $0.97^{*}$ & $0.95^{*}$ & $0.98^{*}$ & 1.00 & $0.93^{*}$ & $0.94^{*}$ \\
Walk score & $(.003)$ & $(.009)$ & $(.007)$ & $(.006)$ & $(.010)$ & $(.009)$ \\
\hline
\end{tabular}

${ }^{*} p<0.05$ (two-tailed); $n=205$ blocks.

Taken as a whole, the findings across all of our analyses suggest that increasing surveillance, reducing crime attractors, and increasing walkability through zoning changes could substantially influence the crime rates on city blocks in Los Angeles.

\section{EMPIRICAL ANALYSIS OF THE EFFECT OF ZONING CHANGES ON CRIME}

Up to this point, we have only inferred a relationship between zoning and crime through a research design that compares crime rates and the built environment across 205 blocks with different land use designations in the same areas of Los Angeles. This methodology is limited because we cannot observe how, if at all, zoning directly influences crime. In other words, our observations take place long after zoning designations were established in these blocks.

Another approach to determine whether zoning affects crime is to observe changes in the crime rate in an area before and after a zoning change occurs, and to compare crime in this area with crime in comparable

214 The count-multiplier or incidence-rate ratios are displayed. Standard errors are noted in parentheses. Each column in the table reflects a separate model of predicted built environment measure on crime. Coefficients are in linear form. "Total" represents the sum of homicide, rape, assault, robbery, theft, theft from automobile, burglary, and auto theft. 
areas that did not undergo a zoning change. ${ }^{215}$ In this way, we can attempt to observe the following counter-factual: what would have happened to crime absent the zoning change? This second study complements our first. While we do not have the kind of rich built-environment observational data in this study that was available in the first study, we do have a substantially larger sample size. We also have crime data over a considerable period of time, which helps identify comparable neighborhoods with similar crime trends before zoning changes.

\section{A. Data}

We obtained detailed data on the zoning designation of every parcel in Los Angeles for the years 2006, 2008, and 2010. ${ }^{216}$ From this data we were able to identify all 361 parcels that changed zoning designations between 2006 and 2010. ${ }^{217}$ Eighty-four percent $(n=304)$ of the zoning changes took place in 2008. The single largest category of zoning changes represented transfers to residential-multiple use $(n=107)$, which accounted for approximately thirty percent of all zoning changes. The second largest category represented zoning changes to commercial zoning use $(n=83)$. The most common form of original designation (i.e., before change) was other uses $(n=201)$.

The 361 affected parcels are located within 180 LAPD reporting districts, which were created to correspond closely to neighborhoods in Los Angeles. ${ }^{218}$ Roughly $18 \%$ ( $n=180)$ of 1010 neighborhoods with a zoning designation had at least one zoning change on a parcel of land between 2006 and $2010 .{ }^{219} \mathrm{We}$

215 The ideal research design would randomize zoning in comparable geographic areas and track the results over time. A randomized field experiment of this kind, however, is not feasible in cities like Los Angeles where zoning decisions are made through a series of regulated legal policy steps.

216 We obtained the zoning data, which serves as the primary independent variable in our analysis, from the City of Los Angeles, Department of City Planning. See ZIMAS, supra note 170. We use our Los Angeles crime data from 2006 to 2010 for the outcome variable.

217 The zoning data has one important limitation: it indicates only whether a parcel underwent a zoning change, but does not indicate the kind of change in actual land use.

218 Cook \& MacDonald, supra note 148, at 450. Reporting districts are the smallest geographic unit for which crime records are available going back to 1994. "Reporting districts occupy more territory in areas where the residential population and housing density is lower. The number of crimes or arrests per reporting district is effectively a rate per unit of resident population in more residential areas." Id. Hereinafter, we refer to reporting districts as "neighborhoods."

219 Reporting district maps from 2005 were used to maintain consistency in boundaries. In 2008 the LAPD changed its boundaries for several reporting districts and added a new police division. We excluded two reporting districts that had no land-use zoning on them. 
aggregated our parcel data to the neighborhood-level crime data. ${ }^{220} \mathrm{We}$ focused on the felony offenses of robbery, assault, burglary, theft from automobiles, and auto theft because these crimes are more likely than others to occur in public settings and are thus more likely to be affected by changes in zoning.

\section{B. Results}

To measure the effect of zoning changes in this study, we needed to construct a comparison group of neighborhoods that is similar to the neighborhoods that underwent a zoning change during the study period. To minimize the chance that our comparison neighborhoods were materially different from our zoning-change neighborhoods, we constructed a comparison group based on historical crime trends for the twelve-year period preceding 2006 (1994-2005). Constructing a comparison group based upon historical crime trends allowed us to control for potential confounding variables that we could not observe with the data available to us. We used twelve years of crime data to maximize the comparability of zoning change and comparison neighborhoods on historic crime trends.

We use group-based modeling of trajectories ${ }^{221}$ to identify groups of neighborhoods that share similar historical crime trends between 1994 and

220 Because we have crime data only at the neighborhood level, we cannot separate out each of the 361 zoning amendments for individual sub-analyses. However, since we are estimating an effect for an entire neighborhood off of a limited number of parcels, our test is biased toward finding no effect.

221 See generally Daniel S. NAgin, Group-Based Modeling of Development 2344 (2005) (explaining that group-based trajectory modeling predicts each group's development and "the probability that a randomly chosen individual from the sampled population is a member of each such group"). The model for each group trajectory takes the following form:

Crime $_{r t}^{j}{ }^{=} \mu^{+} \beta_{\text {time }}^{j}{ }_{r t}{ }^{+} \Psi$ time ${ }_{r t}{ }_{r t}{ }^{+} \lambda$ time $^{3 j}{ }_{r t}+s^{j}{ }_{r t}$

The mean rate of crime for each group $j$ comprising the LAPD reporting districts is modeled as following up to a third-order polynomial in time, where Crime $_{r}$ is a vector of individual reporting district $r$ 's levels of crime at each yearly time point conditional on membership in group $j$, and time, time $^{2}$, and $t i m e^{3}$, are the powers of $r$ 's yearly time points. Given the potential for heterogeneity in the crime patterns, we allowed the trajectories to vary according to this polynomial form to maximize flexibility in the crime trajectories (though this has little consequence since the average crime rate is declining over most of the observational period). Because we are interested in identifying a distinct group of police reporting districts that had zoning changes with those that did not but have similar pre-crime trajectories, this outcome is modeled as a mixture of distributions as shown in the likelihood equation below:

$$
P\left(\text { Crime }_{r t}\right)=\sum_{r} \pi j \Pi_{t} \mathrm{p}^{j}\left(\text { Crime }_{r}\right)
$$

Crime $_{r}$ represents a reporting district $r$ 's vector of crime rates over years 1994 to 2005 (t), $p^{j}\left(\right.$ Crime $\left._{r}\right)$ is the probability of crime rates for each neighborhood given membership in group $j$ and $\pi$ is the population probability of membership in group $j$. The model assumes that, conditional on 
$2005 .{ }^{222}$ In Figure 3 below we show the average crime rate during that period for the four trajectory groups identified by our model. ${ }^{223}$ With the exception of the years 1999 to 2001, all groups were declining in crime regardless of their overall rate.

\section{Figure 3: Trajectories after Sorting Areas into Highest Group Probability}

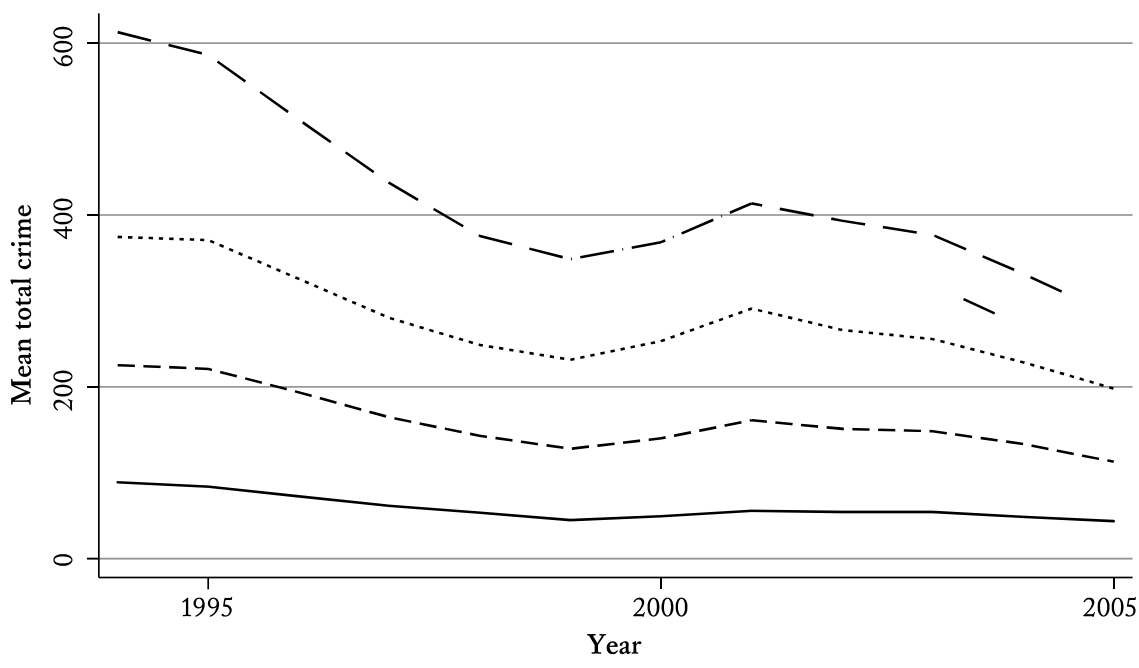

group membership $j$, the measurements for each individual reporting district $r$ at each time point are independent. To identify the optimal number of trajectory groups we used the Bayesian Information Criteria (BIC). This is necessary because when an additional trajectory group is included the parameters have different meanings. The model also provides estimates of the proportion of this population that follows each trajectory and posterior probabilities of group membership for each individual reporting district. The parameters of this model are estimated by a direct maximum likelihood procedure assuming normal distributions available in SAS. For a description of this procedure, see Bobby L. Jones, Daniel S. Nagin \& Kathryn Roeder, $A S A S$ Procedure Based on Mixture Models for Estimating Developmental Trajectories, 29 SOC. METHODS \& RES. 374 (2001).

222 For parsimony, we compare historical crime trends among neighborhoods using total reported felony crimes, defined as the sum of homicide, rape, assault, robbery, burglary, theft from automobiles, and auto theft. We excluded other forms of theft that were not uniformly defined during the 1994 to 2005 period.

223 Neighborhoods were categorized into their trajectory group based upon the highest probability of group membership estimated by the model. 
Next, we fit a propensity score model on all neighborhoods to estimate the probability that a neighborhood had a zoning change conditional on the four trajectory group membership probabilities and on the nineteen regions of Los Angeles in which the neighborhood is located. ${ }^{224}$ Based on the propensity score values, we re-weight comparison neighborhoods ${ }^{225}$ so that the distribution of covariates for comparison neighborhoods matches the distribution of covariates among neighborhoods that experienced a zoning change. This approach gives greater weight to comparison neighborhoods with crime trajectories from 1994 to 2005 that are similar to zoning change neighborhoods and are in the same regions of the city. ${ }^{226}$ Weighting by propensity score adjusts for the potential confounding effect of differences in preexisting crime trends that could be correlated with changes in zoning between 2006 and 2010. After weighting on the propensity score, we have an effective sample size of 956 neighborhoods in the analysis. ${ }^{227}$

Table 9 below shows the standardized differences in trajectory means before and after matching on the propensity score weights. There are average differences in the mean probability of membership in different trajectory groups before matching, but these differences shrink substantially after applying the propensity score weights. ${ }^{228}$ Table 9 demonstrates that the propensity scores effectively weight comparison neighborhoods so that they are comparable to zoning change neighborhoods.

224 For a similar example using propensity scores, see Amelia Haviland, Daniel S. Nagin \& Paul Rosenbaum, Combining Propensity Score Matching and Group-Based Trajectory Analysis in an Observational Study, 12 PSYCHOL. METHODS 247 (2007). See also id. at 250-59 (combining groupbased trajectory modeling with a similar kind of propensity score model, but matching on propensity score rather than weighting on propensity score as we do here). Regions are defined by LAPD divisions: nineteen unique geographic boundaries that represent semi-autonomous areas for which police allocation and planning decisions are made. By including these larger police divisions as geographic controls, we adjust for the average level of crime in different geographic regions.

225 Neighborhoods receiving the zoning change received weights equal to 1; whereas neighborhoods not receiving any zoning change receive inverse probability weights (IPW) equal to $p / 1-p$, according to their propensity score. These IPW values up-weight cases for comparison neighborhoods that have comparable preexisting crime trajectories and are from the same regions of Los Angeles. We lose two reporting districts in the analysis because they had zero crimes reported between 1994 and 2005 and do not contribute to the trajectory model.

226 See Daniel F. McCaffrey et al., Propensity Score Estimation with Boosted Regression for Evaluating Causal Effects in Observational Studies, 9 PsYCHOL. METHODS 403, 405-07 (2004) (describing the analytic technique of propensity score weighting).

227 More specifically, we have 180 neighborhoods that received a zoning change between 2006 and 2010 and a weighted sample of 776 comparison neighborhoods. In effect, we lose the equivalent of 54 neighborhoods through this strategy because no parcels in the LAPD Southwest Division underwent a zoning change.

228 All mean differences are no longer statistically significant $(p<0.05)$ after balancing on the propensity score weights. 
Table 9: Difference Before and After Weighting on the Probability of Trajectory Groups and Regions of City ${ }^{229}$

\begin{tabular}{lccccc} 
& $\begin{array}{c}\text { Zoned Change } \\
(n=180)\end{array}$ & $\begin{array}{c}\text { Comparison } \\
\text { Unweighted } \\
(n=830)\end{array}$ & $\begin{array}{c}\text { Comparison } \\
\text { Weighted } \\
(n=776)\end{array}$ & $\mathrm{D}_{x}$ & $\mathrm{D}_{x m}$ \\
\hline \hline Group 1 & 0.33 & 0.41 & 0.36 & 0.17 & 0.05 \\
Group 2 & 0.37 & 0.33 & 0.35 & 0.08 & 0.04 \\
Group 3 & 0.24 & 0.18 & 0.23 & 0.14 & 0.02 \\
Group 4 & 0.04 & 0.06 & 0.04 & 0.09 & 0.01 \\
\hline
\end{tabular}

After equalizing zoning change neighborhoods and comparison neighborhoods on historical crime trajectory and region of Los Angeles, we estimated the effect of zoning changes on crime. ${ }^{230}$ The results of the analysis, presented in Table 10 below, show that neighborhoods experience substantial reductions in total crime after the introduction of a zoning change. A zoning change is associated with an average of 7.31 fewer crimes per year in a neighborhood. Interpreting this estimate at the sample mean of 99.5 per year crimes suggests that there are approximately seven percent fewer crimes in neighborhoods associated with a zoning change. Although the analysis reveals that assault, robbery, and burglary numbers are lower on average after a zoning change, these effects are not statistically significant. Rather, the effect on total crime appears to be driven mostly by reductions in theft from automobiles and stolen cars. On average, there is roughly a seven-percent reduction in thefts from automobiles and an eleven-percent reduction in stolen motor vehicles among neighborhoods that received some zoning change. Given that most of the zoning changes in the study are conversions to residential uses, these findings suggest that substantial changes in crimes of opportunity take place on the streets as neighborhoods become more residential.

$229 \mathrm{D}_{x}$ represents the mean-standardized difference before weighting on propensity score. $\mathrm{D}_{x m}$ represents the mean-standardized difference after weighting on propensity score.

230 Model 6 is defined as follows:

Crime $_{r t}=\mu+\beta$ Post Change $r t+\Psi_{t}+\lambda_{r}+s_{r t}$.

Crime denotes the crime rate for the neighborhood $r$ at time $t$ (2006-2010), Post Change is an indicator variable that equals one if neighborhood $r$ is in the zoning change group starting in year 2008 or 2010. The parameters $\Psi$ and $\lambda$ represent fixed-effect parameters (dummy variables) to control for year and neighborhood trends. The parameter $\beta$ indicates the effect of a zoning change. Eighty-nine percent $(n=161)$ of the 180 reporting districts that had a zoning change occurred in 2008 
Table 10: Estimated Effect of Zoning Change on Crime in Neighborhoods ${ }^{231}$

\begin{tabular}{lcccccc} 
Crime & Total & Assault & Robbery & $\begin{array}{c}\text { Theft- } \\
\text { from-Auto }\end{array}$ & Burglary & $\begin{array}{c}\text { Auto } \\
\text { Theft }\end{array}$ \\
\hline \hline Zoning & $-7.31^{*}$ & -1.81 & -0.81 & $-2.08^{* *}$ & -0.23 & $-2.28^{*}$ \\
Change & $(3.59)$ & $(1.39)$ & $(.48)$ & $(1.91)$ & $(.69)$ & $(0.98)$ \\
\hline
\end{tabular}

${ }^{*} p<0.05 ;{ }^{* *} p<0.10$ (two-tailed); $n=4766$ police reporting districts.

These findings confirm our earlier block-level results. ${ }^{232}$ We see strong associations between crime and the changes in zoning designations, suggesting that implementing a zoning change has some fundamental bearing on crime patterns. Clearly, this is not simply an effect of switching the law but rather a consequence of changes in land usage afterwards. Because the zoning changes have to occur before the land use changes, zoning enactments appear to have a meaningful impact on crime and are not merely a consequence of existing land use patterns.

\section{DISCUSSION AND IMPLICATIONS}

In this Part, we briefly discuss the implications of our findings for policymakers and the existing literature.

First, we find that zoning is substantially associated with crime rates. This correlation suggests that both researchers and policymakers should pay more attention to the ways in which zoning and other land use policies can affect crime, because even a modest reduction in crime can justify significant up-front research and planning costs. ${ }^{233}$ While we offer some tentative conclusions, our firmest recommendation is that this relationship should be studied in more depth.

Second, we find that residential zoning is associated with substantially lower crime than commercial zoning or mixed-use zoning. Our work echoes past studies that make similar findings about actual land use (as opposed to zoning). However, the higher crime associated with mixed-use zoning has

231 All models include year and reporting district fixed effects. Standard errors adjusted for 959 police reporting district clusters. "Total" represents the sum of homicide, rape, assault, robbery, theft from automobile, burglary, and auto theft.

232 See supra Section III.C.

233 See Paul Heaton, RAND Ctr. on Quality Policing, Hidden in Plain Sight: What Cost of CRIME Research CAN TELl Us AbOUT INVESTING IN Police 4-7 (2010) (summarizing the cost-of-crime literature and the substantial costs associated with criminal activity). 
not always been acknowledged by its proponents. ${ }^{234}$ Logic supports the intuition that commercial uses will deter crime by increasing the "eyes on the street," 235 and commercial and mixed zoning might seem particularly promising for reducing crimes in high-crime neighborhoods. Yet, consistent with prior studies, our research refutes this common-sense notion. Though it may seem logical that mixed-use zoning would reduce crime as compared to housing that is uniformly residential, our research shows that even in relatively high-crime Los Angeles neighborhoods, blocks with commercial uses have more reported crime than those that are uniformly residential.

Third, though mixed-use blocks have more reported crime than uniformly residential blocks, they have substantially less reported crime than commercial blocks. This difference suggests that changing commercially zoned areas to residential zoning may be an effective crime-reduction strategy. Despite Jacobs's hypothesis that commercial establishments reduce crime in residential areas, ${ }^{236}$ the converse appears to be true: residential parcels seem to reduce crime in commercial areas. The results of both of our empirical studies are consistent with this story. In our second study, we found that the decrease in crime associated with zoning changes is predominately correlated with a decrease in thefts of and from automobiles rather than more serious forms of crime. Though these crimes of opportunity are important to reduce, why these crimes show such reduction is unclear, so one should use caution in interpreting these results.

Fourth, our results may also have implications for tax policy. Our findings, using a slightly different methodology, replicate previous findings that commercial areas are responsible for more crime than other areas. Therefore, taxing commercial zones at substantially higher rates to compensate for this externality imposed on the neighborhood may be efficient. Alternatively, policies that encourage business improvement districts (which can be seen as a local tax) may also be warranted to reduce crime associated with commercial areas. ${ }^{237}$

The results of our analysis also have implications for the research literature associated with several of the built environment constructs discussed in Part II. With respect to natural surveillance, we find no support for Jacobs's argument that commercial uses will reduce crime by encouraging a robust

234 See Garnett, The People Paradox, supra note 3, at 50-60; see also ZELINKA \& BRENNAN, supra note 61 , at 53-54 ("Diversity of land uses . . can help create safer and stronger neighborhoods.").

235 See JACOBS, supra note 12.

236 See id. at 36.

237 See MacDonald et al., supra note 148, at 329-30 (finding that business improvement districts reduce violent crimes, especially robbery). 
street life and "eyes on the street." 238 Consistent with previous studies of land use, we find that commercial zoning is generally associated with increased crime. Our study contributes to the literature by replicating this finding in a different city and by employing a more rigorous empirical methodology.

In contrast to this more macro theory of natural surveillance, other scholars have posited that more micro-level interventions that increase visibility will reduce crime. We observed fairly modest support for this theory, finding that blocks with higher predicted levels of natural surveillance had slightly lower crime. However, our study is limited because our ability to measure variations in natural surveillance was limited. Designing streets to have better natural surveillance could lead to crime prevention benefits, but such designs would require a more specific set of zoning regulations than are apparent through our study design.

Numerous writers, probably beginning with Jacobs, have noted the importance of territoriality, or the clear demarcation of space, and a sizeable empirical literature finds that less permeable spaces are associated with lower crime. ${ }^{239}$ Because our study was block-based, we focused on more micro-level measures of territoriality, looking at flowerboxes, flags, and well-tended yards. Perhaps because these measures were associated with commercial uses, we found that greater territoriality is associated with greater crime.

Our study also offers some empirical findings for the sizable literature on physical disorder or incivilities. ${ }^{240}$ Our study focused purely on observed physical disorder, finding that blocks with substantial physical disorder have more crime. Because we used physical disorder predicted by zoning rather than actual physical disorder, we have some confidence that the direction of the causal arrow is from disorder to crime rather than the reverse.

Finally, our findings provide substantial support for a relationship between crime and certain crime attracting land uses. Our measure of crime attraction, as predicted by zoning, was directly associated with crime.

\section{CONCLUSION}

Since King Edward I, commentators have proposed reducing crime by shaping the built environment to reduce opportunities to commit crime. The attractions of this idea are considerable-by reducing crime opportunities

238 See JACOBS, supra note 12 , at 35 .

239 See supra Section II.D.

240 See supra Section II.E. 
at their source, one completely sidesteps the expensive and sometimes ineffective criminal justice system. Urban planners and criminologists have developed a rich literature in this field. Much of it, however, is methodologically limited, and with a few notable exceptions, legal academics have paid only limited attention to this body of research.

In this Article, we reviewed the literature and tested a variety of hypotheses about the relationship between zoning, the built environment, and crime. We found that a significant fraction of reported crime is associated with observable indicators of the built environment related to territoriality, surveillance, and walkability. Put simply, areas with mixed-use zoning have lower reported crime rates than areas zoned for commercial uses only. We also found that exclusively residential blocks exhibit lower reported crime than blocks zoned for commercial or mixed-use, even in relatively high crime neighborhoods.

In the second part of our empirical study, we examined the association between zoning changes and reported crime at the neighborhood level. We found that zoning changes - which were mostly conversions to residential dwellings in commercial- or other use-zoned areas-were associated with reductions in crimes, even when we accounted for historical crime trajectories of neighborhoods.

Together, these findings provide evidence to support the surprisingly prescient intuitions expressed in early prozoning judicial opinions about the effect of commercial establishments in attracting crime. They also suggest that Jacobs had it backwards; rather than commercial uses reducing crime in residential areas we found the converse to be true-residential parcels appear to reduce crime in commercial areas.

Looking forward, our findings suggest that strategic decisions about zoning could be part of the overall crime prevention strategy. In theory, reduced crime will lead to a variety of positive social welfare outcomes, including increased community efficacy, reduced fear of crime, increased outdoor exercise, and better long-term health outcomes.

Despite these promising findings, caution and more research are surely appropriate. We view our findings as tentative first steps in a new field rather than as conclusive answers. Jacobs argued that the appropriate design of urban areas will have a wide range of salutary effects on health and safety. It is therefore worth noting that she herself cautioned against excesses in such thinking:

[T]here is no direct, simple relationship between good housing and good behavior, a fact which the whole tale of the Western world's history, the whole collection of our literature, and the whole fund of observation open 
to any of us should long since have made evident. Good shelter is a useful good in itself, as shelter. When we try to justify good shelter instead on the pretentious ground that it will work social or family miracles we fool ourselves. ${ }^{241}$

In many ways, it is attractive to believe that the physical design of our cities can shape our behavior for the better. But as the built environment receives increased attention, recognizing the complexity of the urban environment - and that one intervention can set off a cascade of unforeseen effects-becomes increasingly important. ${ }^{242}$ Our findings suggest that land use law may be a promising means of reducing crime-one that may, in theory, lead to a host of positive developments. But more research to determine whether our findings are more widely applicable is a critical next step to applying an ancient crime control strategy.

241 JACOBS, supra note 12, at 113 .

242 See id. at 430-35 (discussing how cities are systems of organized complexity and that past urban planning efforts "have consistently mistaken cities as problems of simplicity and disorganized complexity"); $c f$. Jeffrey R. Kling et al., Neighborhood Effects on Crime for Female and Male Youth: Evidence from a Randomized Housing Voucher Experiment, 120 Q.J. ECON 87, 90 (2005) (finding that moving to a neighborhood with less poverty decreases arrests among girls, but increases arrests for boys, at least for property crime). 